\title{
Model-based analysis of the relationship between sun-induced chlorophyll fluorescence and gross primary production for remote sensing applications
}

Yongguang Zhang ${ }^{1,2,3^{*}}$, Luis Guanter ${ }^{3}$, Joseph A. Berry ${ }^{4}$, Christiaan van der Tol ${ }^{5}$, Xi Yang $^{6}$, Jianwu Tang ${ }^{7}$, Fangmin Zhang $^{8}$

${ }^{1}$ Jiangsu Provincial Key Laboratory of Geographic Information Science and Technology, International Institute for Earth System Sciences, Nanjing University, 210023 Nanjing, China;

${ }^{2}$ Jiangsu Center for Collaborative Innovation in Geographical Information Resource Development and Application, 210023 Nanjing, China;

${ }^{3}$ Helmholtz Center Potsdam, GFZ German Research Center for Geosciences, Remote Sensing Section, Telegrafenberg A17, 14473 Potsdam, Germany

${ }^{4}$ Department of Global Ecology, Carnegie Institution for Science, Stanford, California, USA;

${ }^{5}$ International Institute for Geo-Information Science and Earth Observation, P.O. Box 6, 7500 AA Enschede, The Netherlands;

${ }^{6}$ Department of Earth, Environmental, and Planetary Sciences, Brown University, 02912, RI, USA;

${ }^{7}$ The Ecosystems Center, Marine Biological Laboratory, Woods Hole, Massachusetts, USA;

${ }^{8}$ College of Applied Meteorology, Nanjing University of Information Science and Technology, 210044 Nanjing, China

* Corresponding author, phone: +86-25-89681569, E-mail: yongguang_zhang@nju.edu.cn 


\begin{abstract}
Remote sensing of sun-induced chlorophyll fluorescence (SIF) is a novel optical tool for the assessment of terrestrial photosynthesis or gross primary production (GPP). Several recent studies have demonstrated the strong link between GPP and space-borne retrievals of SIF at broad scales. However, critical gaps remain between short-term small-scale mechanistic understanding and seasonal global observations. Here, we present a model-based analysis of the relationship between SIF and GPP across scales for diverse vegetation types and a range of meteorological conditions, with the ultimate focus on reproducing the environmental conditions during remote sensing measurements. The coupled fluorescence-photosynthesis model SCOPE is used to simulate GPP and SIF at the both leaf and canopy levels for 13 flux sites. Analyses were conducted to investigate the effects of temporal scaling, canopy structure, overpass time, and spectral domain on the relationship between SIF and GPP. The simulated SIF is highly non-linear with GPP at the leaf level and instantaneous time scale and tends to linearize when scaling to the canopy level and daily to seasonal. These relationships are consistent across a wide range of vegetation types. The relationship between SIF and GPP is primarily driven by absorbed photosynthetically active radiation (APAR), especially at the seasonal scale, although the photosynthetic efficiency also contributes to strengthen the link between them. The linearization of their relationship from leaf to canopy and averaging over time is because the overall conditions of the canopy fall within the range of the linear responses of GPP and SIF to light and the photosynthetic capacity. Our results further show that the top-of-canopy relationships between simulated SIF and GPP have similar linearity regardless of whether we used the morning or midday satellite overpass times. Field measurements confirmed these findings. In addition, the simulated red SIF at $685 \mathrm{~nm}$ has a similar relationship with GPP as that of far-red SIF at $740 \mathrm{~nm}$ at the canopy level. These findings provide model-based evidence to interpret remotely sensed SIF data and their relationship with GPP.
\end{abstract}


Keywords: Sun-induced chlorophyll fluorescence (SIF), GPP, SCOPE, Photosynthesis, Overpass time, red and far-red SIF 


\section{INTRODUCTION}

Gross primary production (GPP), the rate of $\mathrm{CO}_{2}$ uptake by plants through photosynthesis, represents the largest carbon flux between terrestrial ecosystems and the atmosphere (Beer et al., 2010). Despite the critical importance of photosynthesis for the Earth system, understanding how factors such as climate variability, disturbance history, and water or nutrient availability affect it remains a challenge because of complex interactions and limited GPP measurements at various temporal and spatial scales (Schaefer et al., 2012).

Remote sensing methods have long been used for large-scale assessments of vegetation conditions and types, usually through vegetation indices and other vegetation parameters derived from spectral measurements of surface reflectance (e.g., Huete et al., 2002). Reflectance-based vegetation indices are proxies for vegetation "greenness" and photosynthetic capacity, as they represent a mixed signal from leaf chlorophyll content and canopy green biomass and structure. However, vegetation parameters derived from red and near-infrared (far-red) surface reflectance have no link to actual plant photosynthetic functioning (Grace et al., 2007). Only the photochemical reflectance index (PRI) (Gamon et al., 1992), based on the sensitivity of reflectance at $531 \mathrm{~nm}$ to xanthophyll pigments, has been shown to be sensitive to photosynthetic light use efficiency, although it has not yet been applied to studies at the global scale.

Recent instrumental and methodological developments in the field of space-borne spectroscopy have enabled the measurement of sun-induced chlorophyll fluorescence (SIF) from space, which promises to alleviate current limitations on the monitoring of terrestrial photosynthesis. The SIF signal is emitted by the photosynthetic machinery of healthy vegetation and is thus linked to actual plant photochemistry (Porcar-Castell et al., 2014). SIF observations can, therefore, provide a proxy for photosynthesis not available from any other remote sensing measurements of vegetation (Damm et al., 2010; Rossini et al., 2010; Guanter et al., 2014). Global data sets of SIF have been derived from GOSAT (Joiner et al., 2011; 
Frankenberg et al., 2011; Guanter et al., 2012; Kohler et al., 2015a), GOME-2 (Joiner et al., 2013; Kohler et al., 2015b; Wolanin et al., 2015), and SCIAMACHY (Joiner et al., 2012; Kohler et al., 2015b; Wolanin et al., 2015). The spatial coverage and resolution, wavelength, acquisition time and the amount of data available for analysis depend on the instrument from which they are derived. Single SIF retrievals from those systems are normally aggregated in space and/or time to reduce random retrieval noise.

The potential use of SIF as an indicator of large-scale GPP has been demonstrated for the relatively short period of available global SIF data. For example, high correlations between SIF derived from GOSAT and data-driven GPP estimates at the global and annual scale were shown by Frankenberg et al. (2011) and by Guanter et al. (2012). Lee et al. (2013) used GOSAT SIF data to investigate the seasonality of forest productivity in Amazonia and found that peak productivity occurs during the wet season, which indicates that productivity of the Amazon rainforest is driven by water availability rather than by solar radiation. Using GOME-2 SIF data, Guanter et al. (2014) have shown that SIF has a higher sensitivity to crop photosynthesis than to any other existing remote sensing parameter or model, which has been used to produce new maps of the productivity of the largest crop belts worldwide. More recently, Joiner et al. (2014) demonstrated good agreement between the seasonal cycles of GOME-2 SIF data and flux tower-based GPP estimates. Zhang et al. (2014) have also used GOME-2 SIF data over agricultural areas to demonstrate the feasibility of estimating crop photosynthetic capacity, suggesting the usefulness of SIF in a confined parameter space when certain main properties are known. On the other hand, Koffi et al. (2015) reported a relatively low sensitivity of SIF to photosynthetic capacity in global parameter space when used the Carbon-Cycle Data Assimilation System.

Despite the experimental evidence of a direct and highly linear correlation between spatiotemporal aggregates of remotely-sensed SIF data and large-scale GPP, the relationship 
between instantaneous photosynthesis and SIF is complex (Porcar-Castell et al., 2014; Verrelst et al., 2015) at both leaf and canopy levels. At the leaf level, this relationship is primarily driven by incoming solar radiation, which defines the relative amounts of energy used for photosynthesis, emitted as fluorescence or dissipated as heat in the process of nonphotochemical quenching (NPQ). At light-limiting conditions, most photosynthetically active radiation (PAR, in the 400-700 $\mathrm{nm}$ spectral range) absorbed by chlorophyll is used for photosynthesis, termed as photochemical quenching (PQ), so that fluorescence and NPQ remain low. At high light levels, however, NPQ dominates, and the yields of photosynthesis and SIF decrease with light and tend to co-vary in green and healthy vegetation (van der Tol et al., 2009a). High-light conditions can generally be assumed for the morning and noon overpass times of satellite missions, but this may not apply, e.g., during some parts of the year at high latitudes. In addition, the roles of photorespiration, leaf structure and light scattering properties must also be considered when assessing the relationship between SIF and GPP at the leaf level (Porcar-Castell et al., 2014; Van Wittenberg et al., 2015).

At the canopy level, the effect of canopy structure must also be considered when using remotely-sensed SIF data to estimate large-scale GPP because of the reabsorption of SIF photons emitted in internal canopy layers by other leaves, which depends on leaf optical properties and orientation as well as on the leaf-area index (LAI) and the particular canopy structure. Canopy absorption has a substantial spectral component because red radiation is strongly absorbed by chlorophyll, whereas multiple scattering dominates in the near-infrared (Knyazikhin et al., 2012). Both physiological and canopy structure factors affect the top-ofcanopy GPP-SIF relationship and can, therefore, explain the different scaling factors between the two (Guanter et al., 2012). The temporal trajectories of GPP and SIF might also differ throughout the year at a given location as a function of incoming light, temperature and canopy development stage. Field measurements are usually performed at the leaf level with active methods (Porcar-Castell et al., 2014). Recently, a few ground and airborne campaigns 
have begun to measure SIF at the canopy level in the field (Damm et al., 2010; 2015; Rossini et al., 2010; Rascher, et al., 2015), but continuous, long-term measurements are limited due to technical issues (Meroni et al., 2011; Cogliati et al., 2015; Yang et al., 2015). In this regard, process-based models may be an alternative tool to investigate the complicated relationship between photosynthesis and fluorescence at the seasonal scale in the context of remote sensing SIF applications. As a coupled fluorescence-photosynthesis model, Soil Canopy Observation, Photochemistry and Energy fluxes (SCOPE) has demonstrated the feasibility of simulating SIF and GPP (van der Tol et al., 2009a, b; 2014; Zhang et al., 2014), and can be used as a tool for this purpose.

In this context, the objective of this work is to investigate the relationship between SIF and GPP from a model-based perspective, with emphasis on aspects of special relevance for remote sensing applications. In particular, we explore the relationship between GPP and SIF with attention to their link to absorbed PAR (APAR) as well as to the impact of data acquisition time (as a surrogate for incoming radiation), temporal averaging (as needed to reduce noise in global SIF composites), canopy structure and SIF retrieval wavelength. Our analysis is based on the SCOPE model constrained by vegetation and meteorological data at a number of flux tower sites representing different ecosystems for a wide range of environmental conditions. Field measurements and satellite retrievals of SIF from GOME-2 were also used as validations. This analysis is useful for understanding the differences in the relationships between GPP and SIF from leaf level mechanistic understanding to ecosystemspecific observations.

\section{MATERIALS AND METHODS}

\subsection{Satellite SIF retrievals from GOME-2}

We used SIF data from the GOME-2 instrument onboard Eumetsat's MetOp-A platform. Details of the retrieval of SIF from GOME-2 measurements can be found in Köhler, et al. (2015). We used SIF data from the period between 2007 and 2012 in this work. For each site, 
SIF values were extracted based on the coordinates of the flux tower and averaged to biweekly means when at least 5 SIF retrievals were available within each biweekly period. Although the footprint size of the flux tower $\left(<1 \mathrm{~km}^{2}\right)$ does not match the coarse resolution of GOME-2, we assumed landscape homogeneity within the GOME-2 grid based on the criteria described in section 2.2. We admit that this assumption of landscape homogeneity could lead to biases in the comparison. However, previous studies using the same SIF and flux dataset have demonstrated the overall performance of this assumption (Guanter et al., 2014; Zhang et al., 2014).

\subsection{Flux Tower Sites and Data}

We used 13 flux tower sites which represent different biomes (Table 1). Four of these sites are located in Europe. The remaining sites, located in the contiguous US, are from the AmeriFlux network. The MODIS products for land cover type (MCD12C1, Friedl et al., 2010) and EVI (MOD13C2, Huete et al., 2002) with a spatial resolution of 0.05 degrees were used to determine landscape homogeneity. We selected those sites for which more than $60 \%$ of the GOME-2 pixel area around the flux tower sites corresponds with the biome for each site and for which EVI standard deviation is less than 0.10 (Table 1). These sites represented various terrestrial biomes and climatic conditions: Cropland (C3 and $\mathrm{C} 4 \mathrm{CRO})$, Grassland (C3 and $\mathrm{C} 4$ GRA), Evergreen Needle Forest (ENF), Deciduous Broadleaf Forest (DBF), and Woody Shrubland (WSA) (Table 1).

We obtained Level 4 flux data for the four European sites from the European Fluxes Database Cluster (http://gaia.agraria.unitus.it/). Level 2 flux data were extracted for the US sites from the AmeriFlux website (http://ameriflux.ornl.gov/). Half-hourly or hourly data for $\mathrm{CO}_{2}$ flux and associated meteorological variables were extracted. Gap-filling and fluxpartitioning were all processed using the online tool available at http://www.bgcjena.mpg.de/ MDIwork/eddyproc/ from the Max Planck Institute for Biogeochemistry (MPI- 
BGC). GPP was estimated by partitioning the observed net flux into GPP and ecosystem respiration as described in Reichstein et al. (2005).

Table 1 Basic information for all the flux tower sites *

\begin{tabular}{|c|c|c|c|c|c|c|c|c|c|c|}
\hline $\begin{array}{l}\text { Site } \\
I D\end{array}$ & Latitude & Longitude & Period & $\begin{array}{l}\text { Vegetation } \\
\text { Type }\end{array}$ & $\begin{array}{l}\operatorname{Max} \\
(L C)\end{array}$ & meanEVI & $s d E V I$ & $c v E V I$ & $L A I$ & References \\
\hline $\begin{array}{l}\mathrm{US}- \\
\mathrm{Ne3}\end{array}$ & 41.18 & -96.44 & $\begin{array}{l}2007- \\
2011\end{array}$ & $\begin{array}{l}C R O(C 3 \\
\text { and } C 4)\end{array}$ & $95 \%$ & 0.57 & 0.07 & 0.13 & Field & $\begin{array}{l}\text { Suyker et } \\
\text { al., (2005) }\end{array}$ \\
\hline $\begin{array}{l}\text { US- } \\
B r 1\end{array}$ & 41.97 & -93.69 & $\begin{array}{l}2007- \\
2010\end{array}$ & $\begin{array}{l}C R O(C 3 \\
\text { and } C 4)\end{array}$ & $98 \%$ & 0.58 & 0.08 & 0.14 & $M O D I S$ & $\begin{array}{l}\text { Sauer et } \\
\text { al., (2007) }\end{array}$ \\
\hline $\begin{array}{l}F R- \\
\text { Lq1 }\end{array}$ & 45.64 & 2.74 & $\begin{array}{l}2007- \\
2010\end{array}$ & C3 GRA & $79 \%$ & 0.57 & 0.04 & 0.07 & MODIS & $\begin{array}{l}\text { Hussain, et } \\
\text { al. (2011) }\end{array}$ \\
\hline $\begin{array}{l}\mathrm{HU}- \\
\text { Bug }\end{array}$ & 46.69 & 19.60 & $\begin{array}{l}2007- \\
2008\end{array}$ & C3 GRA & $94 \%$ & 0.35 & 0.03 & 0.10 & $M O D I S$ & $\begin{array}{l}\text { Klumpp, et } \\
\text { al. (2011) }\end{array}$ \\
\hline $\begin{array}{l}\text { FI- } \\
\text { Sod }\end{array}$ & 67.36 & 26.64 & $\begin{array}{l}2007- \\
2008\end{array}$ & $E N F$ & $99 \%$ & 0.38 & 0.03 & 0.08 & $M O D I S$ & $\begin{array}{l}\text { Sulkava, et } \\
\text { al. (2011) }\end{array}$ \\
\hline $\begin{array}{l}R U- \\
\text { Fyo }\end{array}$ & 56.46 & 32.92 & $\begin{array}{l}2007- \\
2009\end{array}$ & $E N F$ & $95 \%$ & 0.55 & 0.04 & 0.07 & $M O D I S$ & $\begin{array}{l}\text { Stoy, et al. } \\
(2014)\end{array}$ \\
\hline $\begin{array}{l}\text { US- } \\
\text { Hol }\end{array}$ & 45.20 & -68.74 & $\begin{array}{l}2007- \\
2008\end{array}$ & $E N F$ & $99 \%$ & 0.58 & 0.04 & 0.08 & $M O D I S$ & $\begin{array}{l}\text { Hollinger, } \\
\text { et al. } \\
\text { (2004) }\end{array}$ \\
\hline $\begin{array}{l}U S- \\
M M S\end{array}$ & 39.32 & -86.41 & $\begin{array}{c}2007- \\
2012\end{array}$ & $D B F$ & $91 \%$ & 0.58 & 0.04 & 0.06 & Field & $\begin{array}{l}\text { Schmid, et } \\
\text { al., (2000) }\end{array}$ \\
\hline $\begin{array}{l}\text { US- } \\
\mathrm{Hal}\end{array}$ & 42.54 & -72.17 & $\begin{array}{l}2012- \\
2013\end{array}$ & $D B F$ & $91 \%$ & 0.54 & 0.05 & 0.09 & Field & $\begin{array}{l}\text { Wofsy, et } \\
\text { al. (1993) }\end{array}$ \\
\hline $\begin{array}{l}U S- \\
S R M\end{array}$ & 31.82 & -110.87 & $\begin{array}{l}2007- \\
2009\end{array}$ & WSA & $96 \%$ & 0.17 & 0.04 & 0.25 & $M O D I S$ & $\begin{array}{l}\text { Scott et al. } \\
(2008)\end{array}$ \\
\hline $\begin{array}{l}\text { US- } \\
\text { Ton }\end{array}$ & 38.43 & -120.97 & $\begin{array}{l}2007- \\
2010\end{array}$ & WSA & $62 \%$ & 0.24 & 0.06 & 0.25 & Field & $\begin{array}{l}X u \text { and } \\
\text { Baldocchi, } \\
\text { (2003) }\end{array}$ \\
\hline $\begin{array}{l}\text { US- } \\
\text { Kon }\end{array}$ & 39.08 & -96.56 & $\begin{array}{l}2007- \\
2009\end{array}$ & C4 GRA & $90 \%$ & 0.48 & 0.05 & 0.11 & $M O D I S$ & $\begin{array}{l}\text { Brunsell, } \\
\text { et al. } \\
\text { (2008) }\end{array}$ \\
\hline $\begin{array}{l}U S- \\
W k g\end{array}$ & 31.74 & -109.94 & $\begin{array}{r}2007- \\
2009\end{array}$ & C4 GRA & $98 \%$ & 0.14 & 0.03 & 0.23 & MODIS & $\begin{array}{l}\text { Scott et al. } \\
(2008)\end{array}$ \\
\hline
\end{tabular}

* LC indicatesLand Cover class, EVI is the MODIS Enhanced Vegetation Index, $\max (\mathrm{LC})$ is the percent of dominant vegetation cover within the GOME-2 pixel, sdEVI is the standard deviation of EVI, and cvEVI is the coefficient of variation of EVI within the GOME-2 pixel.

\subsection{Ground measurements of SIF at the Harvard Forest site}

We used field measurements of SIF at Harvard Forest. The dataset was collected during the growing season of 2013 (Yang et al., 2015). A novel system (FluoSpec) was developed to measure SIF at $760 \mathrm{~nm}$ in the field $5 \mathrm{~m}$ above the top of the forest canopy. The site is $\sim 1.4 \mathrm{~km}$ from the Harvard Forest eddy covariance tower (Environmental Monitoring Station, EMS). A hyper spectrometer with a spectral resolution of $\sim 0.13 \mathrm{~nm}$ between 680 and $775 \mathrm{~nm}$ (HR2000+, Ocean Optics, Inc.) was used. The measurements were completed from June 21 to October 26, 2013. Details of the system and measurements are reported in Yang et al. (2015). 
We used their field SIF measurements and flux data from the EMS site as a comparison to our SCOPE simulations. Clear sky days were defined as days when the daily mean diffuse PAR fraction was $<50 \%$ (Yang et al., 2015).

\subsection{The SCOPE model and input parameters}

We performed the simulations for all flux sites using SCOPE to model photosynthesis and fluorescence at both leaf and canopy levels. SCOPE is a vertical (1-D) schematization of the vegetation that simulates radiative transfer and the exchange of heat, $\mathrm{CO}_{2}$ and $\mathrm{H}_{2} \mathrm{O}$ between soil, vegetation and the atmosphere (van der Tol et al., 2009b). The reflectance and transmittance of the leaves are calculated with the module Fluspect (van der Tol et al., 2009b), which is an extension of the PROSPECT model (Jacquemoud et al., 2009). This extension consists of the calculation of the scattering of chlorophyll fluorescence within the leaf. The radiative transfer of incident (solar and sky) light through the canopy was calculated with the SAIL model (Verhoef, 1984), in which 60 elementary layers, 13 leaf zenith and 36 leaf azimuth classes are distinguished. The incident light on each leaf was further used to compute the internally generated radiation per leaf layer and leaf inclination class as: thermal radiation (using Planck’s law) and chlorophyll fluorescence (using Fluspect).

One input of the radiative transfer modules is the fluorescence emission efficiency $\varepsilon$, which is the probability that an absorbed photon in the photosynthetically active region of the spectrum, is re-emitted as fluorescence. A constant $\varepsilon$ implies that the simulated SIF is exactly proportional to APAR. SCOPE assumes that $\varepsilon$ of photosystem I (PS-I) is constant, and hence that the SIF produced by PS-I is proportional to APAR. The emission efficiency of PS-II is not kept constant, but it is calculated using a semi-empirical model for photosynthesis and fluorescence emission based on leaf-level measurements of gas exchange and active fluorescence measurement techniques. In previous versions, the model of van der Tol et al. (2009b) was used, but in the version used here, the model of van der Tol et al. (2014) has been 
used. This model simulates the fate of absorbed photons, with three dissipation pathways: photochemical quenching (PQ), non-photochemical quenching (NPQ), and fluorescence. The probabilities are calculated with rate coefficients $K$ with subscripts $f$ for fluorescence, $p q$ for photochemical quenching and $n p q$ for non-photochemical quenching:

$$
\varepsilon \propto \frac{K_{f}}{K_{f}+K_{p q}+K_{n p q}}
$$

$K_{f}$ is a property of the chlorophyll molecule and is a constant, but $K_{p q}$ and $K_{n p q}$ both vary. $K_{p q}$ varies because the efficiency of photochemical use of photons depends on the capacity of the photosystems to transport electrons. $K_{n p q}$ consists of a constitutive thermal dissipation component $\left(K_{d}\right)$, which is present in dark-adapted plants, and a variable heat dissipation component $\left(K_{n}\right)$, which is controlled by photosystem electron transport regulation mechanisms. In the model of van der Tol et al. (2014), two alternative empirical calibrations for $K_{n}$ are available. Here, we use a parameterization calibrated to outdoor measurements by Flexas et al. (2002) on plants under variable drought conditions as a function of the light saturation of photosynthesis $\mathrm{x}$ :

$$
K_{n p q}=v K_{n}^{o} \quad \text { with } \quad v=\frac{(1+\beta) x^{\alpha}}{\beta+x^{\alpha}}
$$

where $K_{n}^{o}, \alpha$ and $\beta$ are fitting parameters with values $K_{n}^{o}=5.01, \alpha=1.93$ and $\beta=10$. The variable $x$ is crucial; it is the ratio of actual over potential (light limited) photochemistry and is calculated from the photosynthesis model. The variability of $\varepsilon$ for PS-II is responsible for the fact that the emitted fluorescence is not always proportional to absorbed PAR. The value of $\varepsilon$ is calculated from $x$, which in turn depends on the maximum carboxylation capacity $V_{\text {cmax }}$, the irradiance on the leaf, stomata aperture and leaf temperature. An updated version of the SCOPE model was used here (v1.54). More details are provided in van der Tol et al. (2009b, 
2014). The model performs well in simulations of GPP and SIF when compared to field data (Fig. S1).

The input parameters for SCOPE include meteorological forcing (incoming shortwave and long-wave radiation, air temperature and pressure, humidity, wind speed, and $\mathrm{CO}_{2}$ concentration), LAI, leaf angle distribution, leaf chlorophyll content (Cab), stomatal conductance parameter $(\mathrm{m})$, and $\mathrm{V}_{\mathrm{cmax}}$. Meteorological data were available from the flux site measurements. Leaf angle distribution is assumed to be spherical for all vegetation types, which is a good approximation for most forest canopies and crops (e.g., Wang and Jarvis, 1990). An estimation of Cab was inverted from vegetation indices (EVI and MERIS Terrestrial Chlorophyll Index, MTCI, Dash et al., 2004) as described in Zhang et al. (2014). The values of $\mathrm{V}_{\mathrm{cmax}}$ were set to constant for each biome, following Wullschleger (1993) and Kattge et al. (2009) (Table 2). LAI and its seasonal variations were either derived from sitespecific websites or from MODIS LAI products (http://public.ornl.gov/fluxnet/modis.cfm). Canopy height and leaf width size were obtained from the published literature, internet websites or personal communication with the primary investigators. Other parameters within the SCOPE model, such as reflectance and transmittance of vegetation and soil, were set to default values.

Table 2. Maximum carboxylation capacity (Vcmax) for each plant function type (PFT)

\begin{tabular}{ccc}
\hline PFT number & PFT & $\operatorname{Vcmax}\left(\mu \mathrm{mol} \mathrm{m}^{-2} \mathrm{~s}^{-1}\right)$ \\
\hline 1 & C4CRO & 39.0 \\
2 & C3CRO & 100.0 \\
3 & C4GRA & 30.0 \\
4 & C3GRA & 52.0 \\
5 & ENF & 62.5 \\
6 & DBF & 57.7 \\
7 & WSA & 54.0
\end{tabular}


In addition, a one-by-one sensitivity analysis was performed for a $\mathrm{C} 3$ plant to evaluate the responses of GPP and SIF to $\mathrm{V}_{\mathrm{cmax}}$ and light conditions at the leaf level, and the impacts of canopy structure, LAI, and Cab on the relationship between GPP and SIF at the canopy level. We first performed the simulations with changing $\mathrm{V}_{\mathrm{cmax}}$ while keeping the light condition constant at different levels. Then, the second simulation is done with changing light (Rin) by keeping $\mathrm{V}_{\mathrm{cmax}}$ constant at different levels. All other parameters were set to default values of a standard case. To further investigate the factors impacting the slope between GPP and SIF, we conducted another sensitivity analysis with SCOPE at canopy level. Four main factors impacting SIF and GPP are leaf properties and canopy structural variables including Cab, leaf inclination (LIDFa), LAI and $\mathrm{V}_{\mathrm{cmax}}$ (Verrelst et al., 2015).Simulations were made by changing each of the four parameters within a range in Table 3 and keeping other parameters at default values.

Table 3. Parameters of the SCOPE model for the sensitivity simulations and their range.

\begin{tabular}{ccccc}
\hline Parameters & Symbol & Units & Range & Default \\
\hline Chlorophyll a+b content & $C_{a b}$ & $\mu \mathrm{g} \mathrm{cm}^{-2}$ & $1-90$ & 40 \\
Maximum carboxylation capacity & Vcmax & $\mu \mathrm{mol} \mathrm{m}^{-2} \mathrm{~s}^{-1}$ & $1-200$ & 100 \\
Leaf area index & LAI & $/$ & $0.1-7$ & 3 \\
Leaf angle distribution parameter a & $L I D F_{a}$ & $/$ & $-1-1$ & -0.35 \\
\hline
\end{tabular}

\subsection{Analysis}

The SCOPE simulations are at half-hourly or hourly steps for all years and sites. Because plants do not perform photosynthesis or emit fluorescence at night and because satellite observations are only obtained during the day, we only ran simulations during the day (8 am to $6 \mathrm{pm}$ ) for the further analysis of the relationship between GPP and SIF at both the leaf and canopy levels. Hence, the daily mean values of GPP and SIF are the average of the daytime values only. To evaluate the relationship between GPP and SIF across multiple temporal scales for different biomes, we aggregated the daytime instantaneous values (half-hourly or hourly) of GPP and SIF into different time bins (daily and 16 days). To investigate the effects 
of different satellite overpass times on the relationship between GPP and SIF, we compared the simulations in the morning (9-11 am) and at midday (1-2 pm). Statistical and regression analysis is made with Matlab Statistics Toolbox 2014b (The MathWorks, Inc.). In addition, to be consistent with more widely used GOME-2 SIF data, we used SIF at $740 \mathrm{~nm}$, if no other spectral domain is specified.

\section{RESULTS And DISCUSSION}

\subsection{Assessment of the relationships between GPP and SIF across different scales}

Scatter plots between canopy-level GPP and SIF from hourly to 16-day time scales are shown in Fig. 1 for the measurements at the Harvard Forest flux site. The ground measurements of the hourly data are somewhat noisier (cyan), and an obvious curvilinear fit between GPP and SIF can be observed both for all days and for clear sky days, which had better goodness of fit (rmse $\sim 5.3$ and $\mathrm{r}^{2} \sim 0.55$ compared to a linear model with rmse $\sim 6.0$ and $\mathrm{r}^{2} \sim 0.42$ in Fig. 1). However, after aggregating hourly to daily or 16-days, the GPP-SIF relationship showed an increasing linearity both for all days and for clear sky days (Fig. 1). It also shows that both SIF and GPP tend to become more normal after averaging over time (Fig. S2). In addition, the GPP-SIF relationship became stronger during sunny days than cloudy days (Fig. 1), especially at the daily and 16-day time scales.
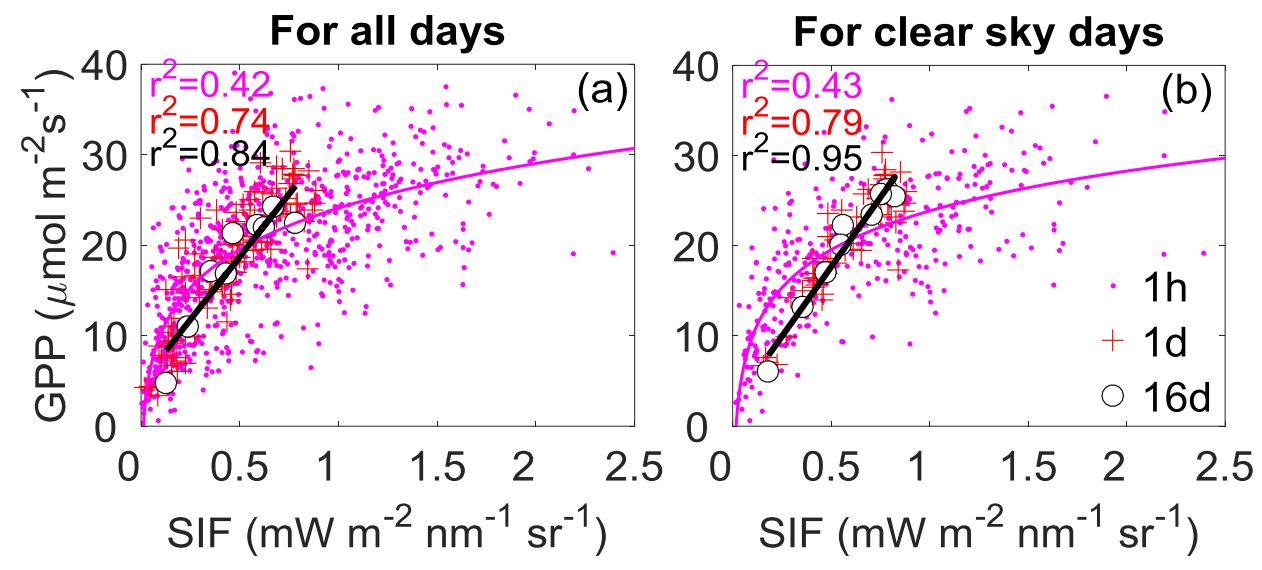

Fig.1 (a) Relationships between flux tower GPP and field measured SIF (at $760 \mathrm{~nm}$ ) for all days from hourly to 16-day steps at the Harvard Forest site for 2013 for all daytime; (b) for the clear sky days. The black line is a linear regression for the 16-day time series. The cyan 
line is a power model fit for the hourly data. The different colors (cyan, green, and white) represent hourly (1h), daily (1d) and 16-day (16d) time scales, respectively. $\mathrm{r}^{2}$ is the coefficient of linear regression.

To determine why such linearization occurs and if it is valid for other vegetation types, a sensitivity analysis was performed using simulations with the SCOPE model at the leaf level. We investigated how both GPP and SIF respond to photosynthetic capacity $\left(V_{\text {cmax }}\right)$ and light conditions (Fig. 2). When varying $V_{\text {cmax }}$ at the constant light, there are a non-zero intercept of the response for SIF and an intercept at zero for GPP (Fig. 2a). Under light-limiting conditions, both GPP and SIF are saturated at lower photosynthetic capacity, whereas the saturation begins at higher $V_{\text {cmax }}$ with increasing radiation (Fig.2a). Fig.2b shows the changes in GPP and SIF in response to APAR at different levels of $V_{c m a x}$. Both GPP and SIF are zero when APAR is zero, and they both increase with APAR. At light-limiting conditions, GPP is dependent on APAR but not $V_{\text {cmax }}$. However, at higher light conditions, GPP is dependent on $V_{\text {cmax }}$, but the slope extrapolates to a positive GPP, and GPP is independent of APAR.

Meanwhile, light saturation of GPP occurs under lower light conditions with lower $V_{c m a x}$, and the value of saturated irradiance rises with increasing $V_{\text {cmax }}$ (Fig.2b). On the other hand, SIF continuously increases with APAR, but the slope of line flattens above the saturation point. The sensitivity of SIF to $V_{c m a x}$ at the leaf level is similar to that at the canopy level (Koffi et al., 2015), but with higher sensitivity under higher light conditions (Fig. 2b).
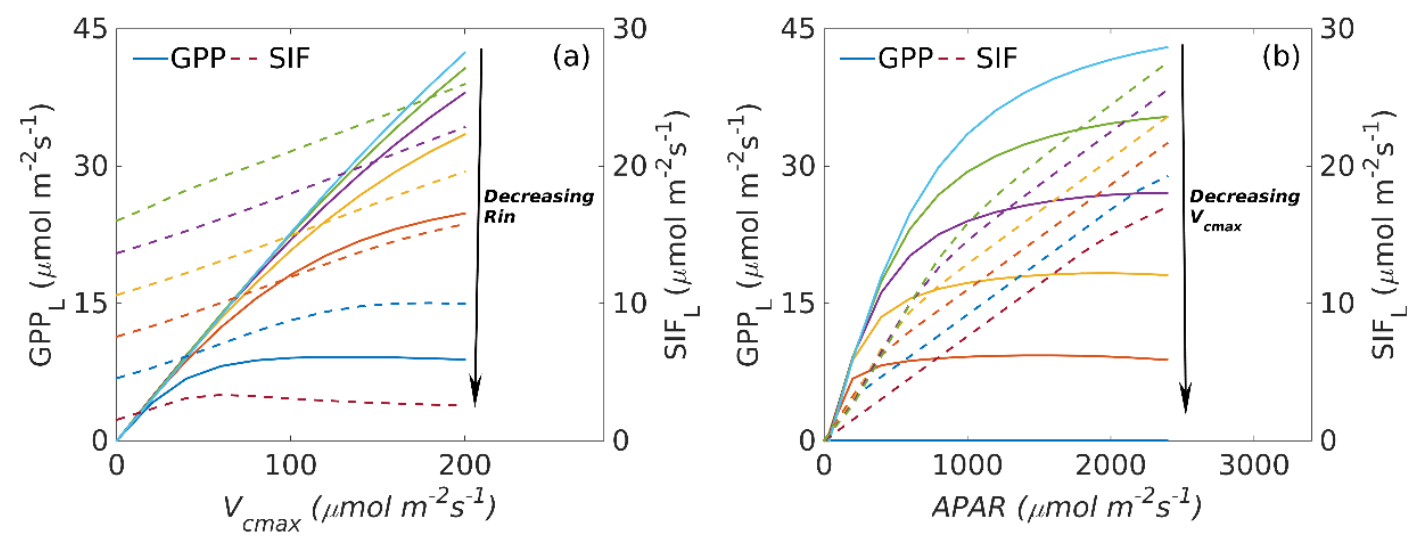

Fig. 2. Modeled GPP $\left(\mathrm{GPP}_{\mathrm{L}}\right)$ and SIF $\left(\mathrm{SIF}_{\mathrm{L}}\right)$ at the leaf level (a) as a function of $V_{\text {cmax }}$ at different levels of light (Rin): 100, 300, 500, 700, 900 and $1100 \mathrm{~W} \mathrm{~m}^{-2}$; and (b) as a function 
of APAR at different levels of $V_{\text {cmax }}:$ 0, 40, 80, 120, 160 and $200 \mu \mathrm{mol} \mathrm{m}^{-2} \mathrm{~s}^{-1}$. Leaf-level SIF is an approximation of fluorescence flux, which is the product of fluorescence yield $\left(\Phi_{F t}\right)$ and APAR.

Figure 2 also illustrates that there is a break point in the slope of GPP-APAR (or SIFAPAR) that occurs with increasing APAR as $V_{c m a x}$ increases. This is the point at which the response of GPP transits from being light limited to light saturated. The point at which this transition occurs is related to the $V_{c m a x}$, and the slope of the continued increase in SIF above saturation is related to the parameterization of $K_{n p q}$. This regulation only disposes of a portion of the excess APAR. Such non-linear coupling between GPP and SIF suggests that the slope of their relationship will vary with changing $V_{c m a x}$. The break point at saturation distinguishes the range where the relationship between GPP and SIF changes from linear to non-linear. Below this point, both GPP and SIF have a linear dependence on $V_{c m a x}$ and APAR and, hence, they are linearly correlated. Above this point, a non-linear relationship occurs between GPP and SIF.

These different responses of GPP and SIF to APAR are due to the covariance of fluorescence yield $\left(\Phi_{F t}\right)$ and photochemical yield $\left(\Phi_{p}\right)$ with irradiance conditions. At short time scales (e.g., instantaneous as minutes to hours), a complicated "boomerang" shaped relationship exists between steady state $\Phi_{F t}$ and $\Phi_{p}$ at the leaf level, depending on whether the light conditions are low or high, as shown in Fig. 3 for an example of a crop and DBF. Under light-limiting conditions, $\Phi_{F t}$ is negatively correlated with $\Phi_{p}$, which is greater than 0.6 (Fig. 3 ), because photochemistry (PQ) dominates with decreasing $\Phi_{p}$ in response to increasing absorbed light, whereas $\Phi_{F t}$ increases (Porcar-Castell et al., 2008; van der Tol et al., 2014). However, both $\Phi_{p}$ and $\Phi_{F t}$ decrease under high light conditions, and they are positively related (Fig. 3) due to the dominance of NPQ. These results agree well with those of Damm et al. (2015) and Lee et al. (2015). Such different responses of leaf-level $\Phi_{p}$ and $\Phi_{F t}$ to increasing light lead to earlier light saturation for GPP than for SIF with APAR. 

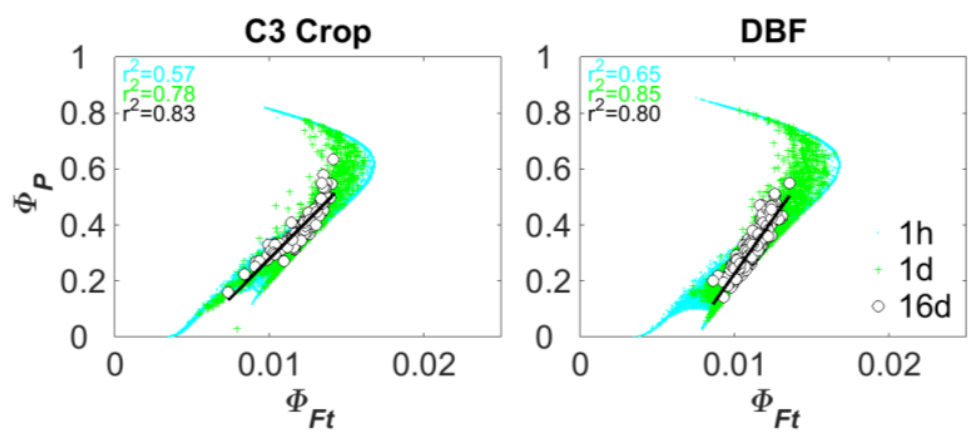

Fig. 3. Modeled leaf level relationships of fluorescence yield $\left(\Phi_{F t}\right)$ and photochemical yield $\left(\Phi_{p}\right)$ for two selected biomes (C3 crop and DBF). The different colors (cyan, green, and black) represent hourly (1h), daily (1d) and 16-day (16d) time scales, respectively. $r^{2}$ is the coefficient of linear regression. The solid black line is the fit for 16-day time scale. See the plots for other biomes in Fig. S5 in the Supplement.

To illustrate how the relationship between GPP and SIF tends to linearize when considered at the canopy and seasonal scales under natural conditions, further simulations were performed with field data for all sites during the period shown in Table 1. Simulation results from a selection of these sites are shown in Fig. 4. The results for other biomes are shown in the Supplement (Fig. S3-5). Figure 4 (a-d) shows highly non-linear (curvilinear) relationships between hourly GPP and SIF (cyan color). The curvilinear relationship is more obvious for vegetation types other than crops. The simulations demonstrate a general pattern for a wide range of vegetation types and climatic conditions (Fig. S3 in the Supplement). The different responses of leaf-level $\Phi_{\mathrm{p}}$ and $\Phi_{\mathrm{Ft}}$ to increasing light may lead to the asymptotic relationship between hourly GPP and SIF (Fig. 4a-d, cyan color) because GPP tends to be saturated earlier under high illumination conditions, whereas fluorescence flux continuously increases in response to increasing light intensity until a later saturation point (Fig. 2). 

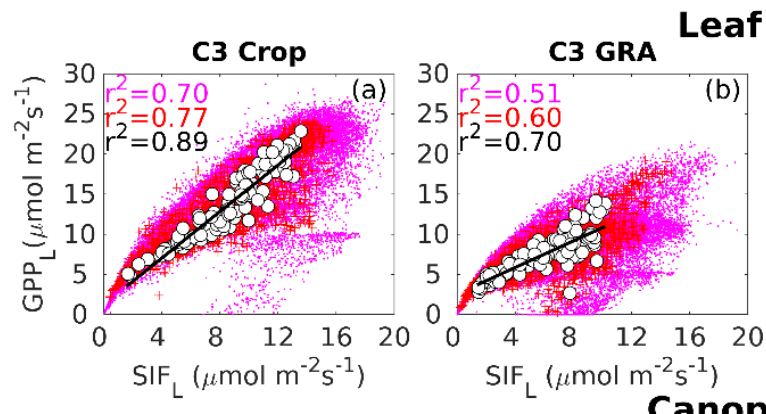

\section{Leaf level}
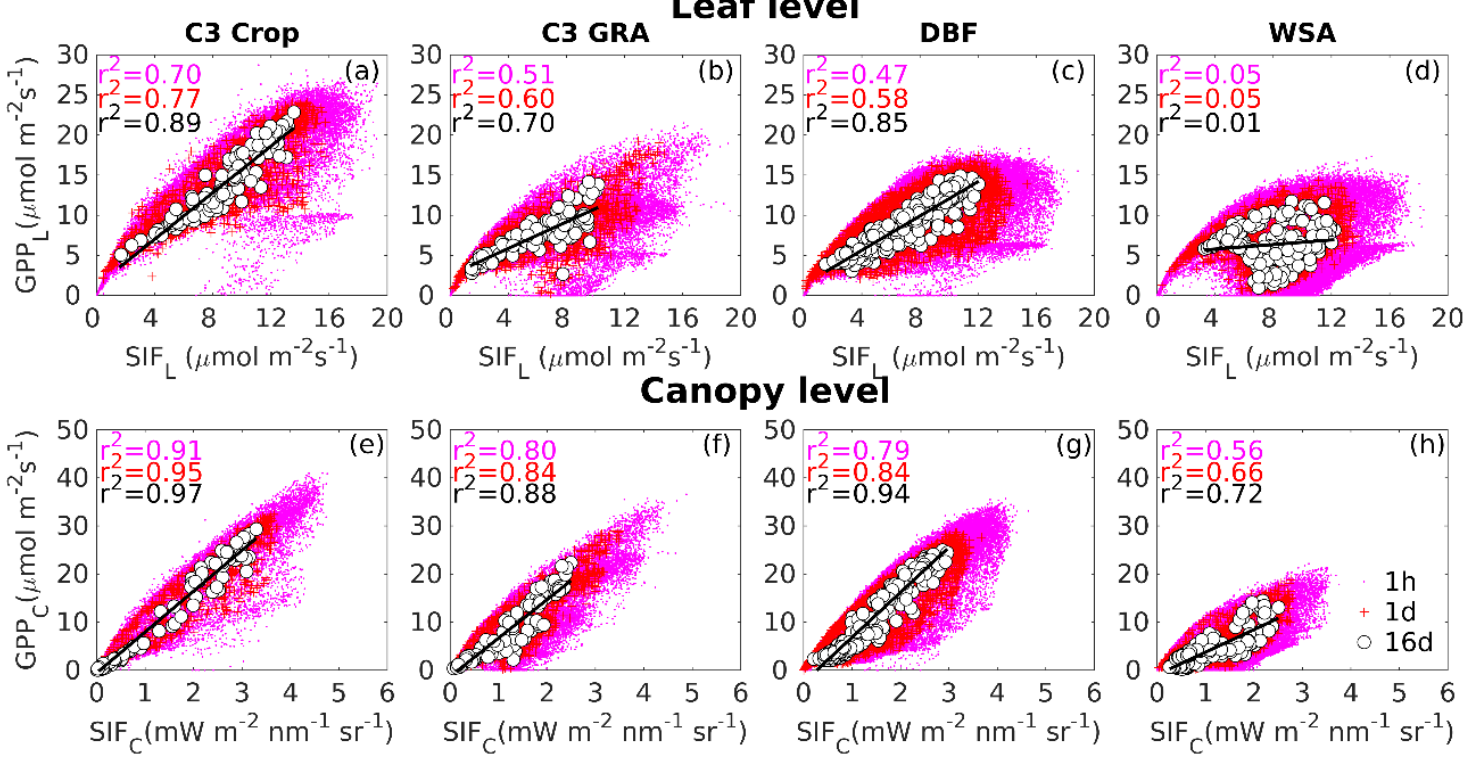

Fig. 4. Changes in the relationships between GPP and SIF from leaf to canopy level and from instantaneous to synoptic scale for four selected biomes from SCOPE simulations. $\mathrm{SIF}_{\mathrm{L}}$, total leaf level fluorescence flux, was calculated as APAR $* \Phi_{F t}$. Leaf level GPP $\left(\mathrm{GPP}_{\mathrm{L}}\right)$ was directly obtained from the SCOPE output. GPP and SIF $\left(\mathrm{GPP}_{\mathrm{C}}\right.$ and $\left.\mathrm{SIF}_{\mathrm{C}}\right)$ at the canopy level are from SCOPE output. The different colors (magenta, red, and white) represent hourly (1h), daily (1d) and 16-day (16d) time scales, respectively. $\mathrm{r}^{2}$ is the coefficient of linear regression. The solid black line is the fit for the 16-day time scale.

The modeled GPP-SIF relationship was consistent with the linearization effect when averaging over time from the field measurements (Fig. 1). Figure 4 shows how the GPP-SIF relationships change when scaling from hourly to synoptic and seasonal for both the leaf and canopy levels. Here, leaf level SIF $\left(\mathrm{SIF}_{\mathrm{L}}\right)$ is the total fluorescence flux and calculated as $\operatorname{APAR} * \Phi_{F t}$ at the leaf level, whereas canopy level SIF $\left(\mathrm{SIF}_{\mathrm{C}}\right)$ is top-of-canopy fluorescence at $740 \mathrm{~nm}$ at the nadir observation from the SCOPE output. After aggregating hourly to daily and 16-day scales, the relationship between GPP and SIF becomes more linear with increasing $\mathrm{r}^{2}$ and decreasing rmse (Fig. 4). The relationship becomes stronger for data averaged over 16 days than for daily. In contrast, the GPP-SIF relationship at the canopy level also tends to become more linear with higher $r^{2}$ for the linear regression compared with the leaf level relationship (Fig. 4 and Fig. S4). For woody shrubland, such changes are more obvious in the highly non-linear instantaneous relationship between GPP and SIF at the leaf level $\left(r^{2}=0.05\right.$, rmse $\left.=4.15\right)$ and more linear at the canopy level $\left(r^{2}=0.56\right.$, rmse $\left.=2.63\right)($ Fig. $4 \mathrm{~d}$ and $4 \mathrm{~h}$ ). The linearization of the GPP-SIF relationship when averaging over time is mainly 
due to the dependency of both GPP and SIF on APAR. As expected, both GPP and SIF increase with APAR at the leaf level (Fig. 5a-d). However, light saturation occurred earlier for GPP than SIF with APAR. A non-linear (i.e., curvilinear) relationship exists between GPP and APAR (Fig. 5a and b), whereas a fairly positive linear correlation occurs between SIF and APAR at the leaf level (Fig.5c and d). A comparison of Fig. 5 to Fig. 4 (a, c) demonstrates that the differences between GPP and SIF in response to APAR caused the curvilinear relationship between hourly GPP and SIF at the leaf level. However, as shown in Fig. 5, after aggregation over different time scales, the curvilinear relationship between GPP and APAR approaches linearity for both the leaf and canopy levels. Figure 5 also illustrates that temporal aggregation reduces APAR, decreasing light saturation at the leaf and canopy levels. This result is in accordance with well-known observations that increasing the time scale linearizes the light response curve of photosynthesis (e.g., Ruimy et al., 1995; Baldocchi and Amthor, 2001).
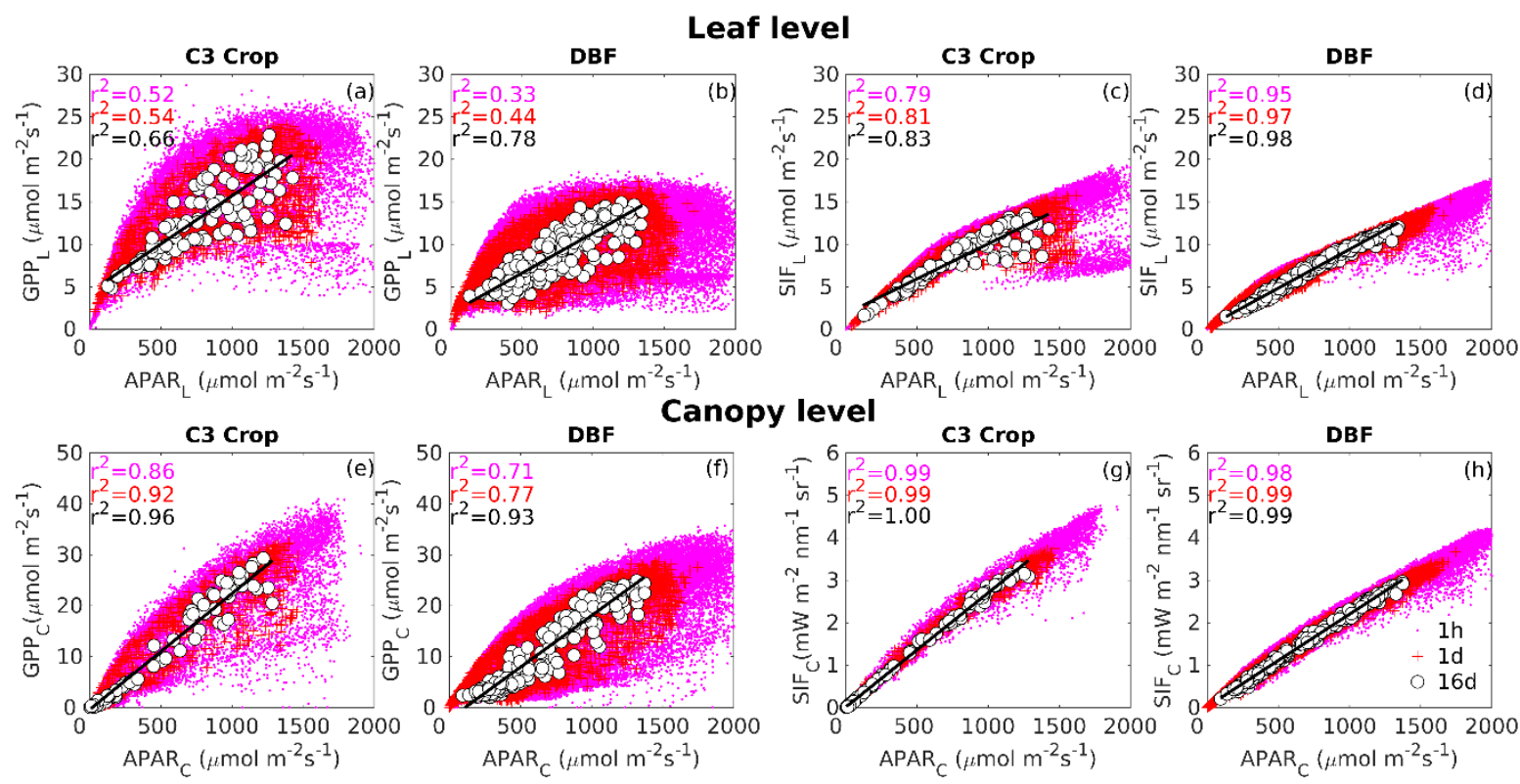

Fig. 5. Leaf and canopy level relationships between GPP\&SIF and APAR for two selected biomes (hourly, daily, and 16-day time scales) from SCOPE simulations. The different colors (magenta, red, and white) represent hourly (1h), daily (1d) and 16-day (16d) scales, respectively. The solid black line is the fit for the 16-day time scale. See the plots for other biomes in Fig. S6-9 in the Supplement. 
Similarly, the linearization of the GPP-SIF relationship when scaling from leaf to canopy level may be partially explained by the effects of canopy structure and the dependence on APAR. The leaf-level simulations represent the conditions for sunlit leaves exposed to high irradiance, which falls in the range of non-linearity (above the saturation point for photosynthesis) (Fig. 2). In Figure 2, the sensitivity simulations consider a wider range of environmental and biochemical variation than may have occurred at the time of satellite observation. The actual variation of $V_{c m a x}$ and leaf angle within a canopy could be such that the light saturation point of the canopy is similar to the maximum light received at the time of satellite overpass. Hence, the overall conditions of a canopy fall within the linear range, especially when averaging over space and time, resulting in the linear correlation of GPP and SIF even though a non-linear relationship might be expected if a wider variation of $V_{\text {cmax }}$ was considered. This effect is demonstrated by the light response curve of GPP and SIF with APAR at the leaf and canopy levels (Fig. 5). Figure 5(e-h) shows that the saturation of GPP to APAR is generally alleviated at the canopy level. A curvilinear relationship is still obtained between instantaneous GPP and APAR. However, a relatively strong linear correlation of $r^{2}>$ 0.71 is derived (Fig.5e-f) suggesting that the excursions into non-linear responses observed at the leaf level still exist at the canopy level but they are combined with conditions where linear correlation occurs, and this effect increases from leaf to canopy level. The results here are consistent with a recent study (Damm, et al., 2015), which used a few days of airborne observations for grassland, cropland, and temperate mixed forest. Our study provides a more theoretical analysis of the linearization effect of the averaging and scaling with continuous field measurements and simulations for a broader range of vegetation types.

In addition, the simulations indicate that APAR, primarily green APAR, may be the primary driver of the relationship between simulated GPP and SIF at the canopy level, especially at the seasonal scale. The correlation between GPP and APAR is generally less than that between GPP and SIF at both the leaf and canopy levels from hourly to seasonal 
scales (Fig. 6), indicating that SIF is related to APAR as well as to photosynthetic light use efficiency. This agrees well with previous results from field measurements (Yang et al., 2015). The simulations also support the arguments in Rascher et al. (2015), which claimed that canopy SIF emission is related to APAR and actual photosynthetic efficiency. With increasing aggregation of time scales, however, the dependence of SIF on APAR tends to dominate, as characterized by the closer correlation $\left(r^{2}\right)$ of GPP and SIF with GPP and APAR at both leaf and canopy levels (Fig. 6b and d). This is supported by the field measurements at Harvard Forest (Fig. 6d inset).

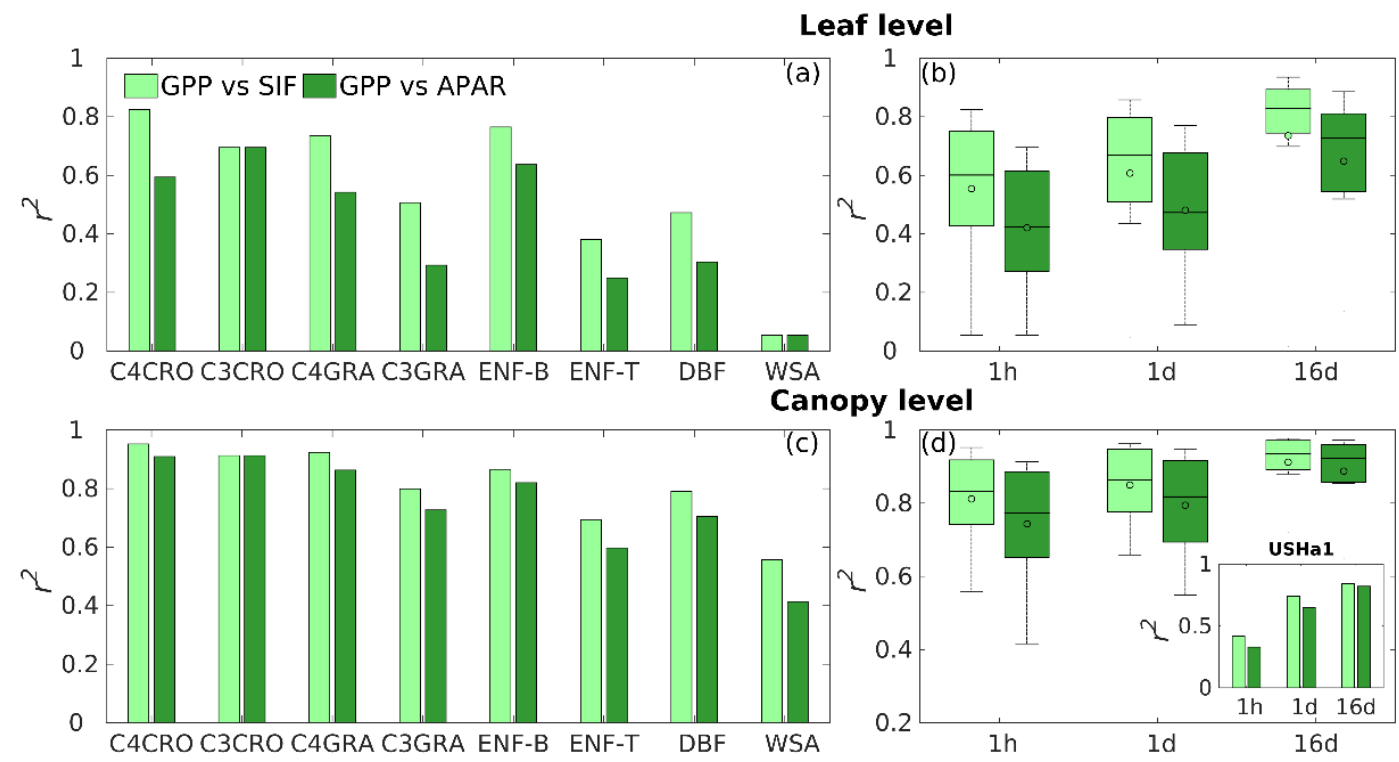

Fig. 6 Leaf (a) and canopy (c) level linear correlation $\left(\mathrm{r}^{2}\right)$ between GPP and SIF or APAR across biomes at instantaneous (hourly) time scales from SCOPE simulations. (b) and (d) are the averages of all biomes at hourly (1h), daily (1d) and 16-day (16d) time scales for the leaf and canopy levels, respectively. The inset plot in (d) is the correlation between GPP and SIF or APAR from the field measurements at Harvard Forest.

We also explored the factors impacting the slope between GPP and NIR SIF with a sensitivity analysis at the canopy level. Figure 7 demonstrates the sensitivity of the hourly GPP-SIF relationship to LAI, $\mathrm{V}_{\mathrm{cmax}}$, Cab and leaf inclination angle (LIDFa) at the canopy level for a C3 plant under the different light conditions. The variation of the slope is significant due to LAI and $\mathrm{V}_{\mathrm{cmax}}$, especially at their lower values. The slope between GPP and SIF becomes larger with higher LAI and $\mathrm{V}_{\mathrm{cmax}}$. The weaker sensitivity of the slope to higher 
LAI (> 4) is because both GPP and SIF are not sensitive to higher LAI (Koffi et al., 2015). As for $\mathrm{Cab}$, the slope tends to become smaller with increasing $\mathrm{Cab}$, but only sensitive when $\mathrm{Cab}$ is less than $20 \mu \mathrm{g} \mathrm{cm}^{-2}$. This is due to the weaker sensitivity of top-of-canopy reflectance and transmittance to Cab when calculating APAR in SCOPE (Koffi et al., 2015). In addition to LAI, another important structural factor is leaf angle distributions (LAD). Figure 7d indicates that the slope between GPP and SIF is also sensitive to LIFDa, approaching smaller with LAD from erectophile to planophile. This is due to the fact that SIF from leaves with erectophile LAD is less than that from planophile. However, different leaf angle distributions were found to have relatively little influences on the modeled canopy photosynthesis (e.g., Wang \& Jarvis, 1990; Baldocchi \& Meyers, 1998). The simulations here indicates that both canopy structure and leaf properties impact the slope between GPP and SIF, but with different sensitivity.
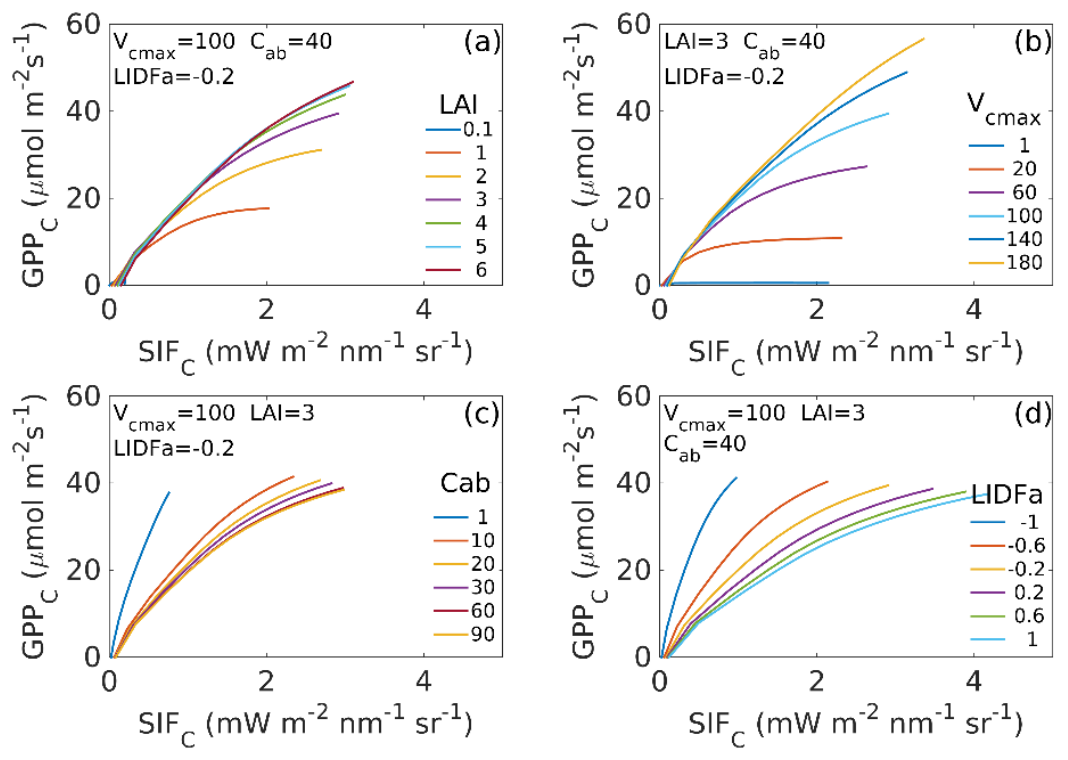

Fig. 7. The sensitivity of the relationship between hourly GPP and SIF at $740 \mathrm{~nm}$ to LAI (a), $\mathrm{V}_{\mathrm{cmax}}(\mathrm{b}), \mathrm{C}_{\mathrm{ab}}(\mathrm{c})$, and LIDFa (d) at the canopy level for a C3 plant from simulations. The radiation (Rin) is from 100 to $1200 \mathrm{~W} \mathrm{~m}^{-2}$.

\subsection{Effects of overpass time on the relationship between GPP and SIF}

Currently, morning (e.g., GOME-2) and midday (e.g., GOSAT, OCO2) satellite observations of SIF are collected. A linear relationship has been found between flux tower 
GPP and SIF retrievals from GOME-2 for cropland (Guanter et al., 2014), by comparing SIF measured at satellite overpass time (morning or midday) several times in a week or month with GPP integrated for the week or month. We also found fairly linear relations of flux tower GPP and GOME-2 SIF for all biomes used in this study (Fig. 8). Because both GPP and SIF are dynamic in response to changing environmental conditions, it is useful to evaluate the effects of overpass time on their relationship.

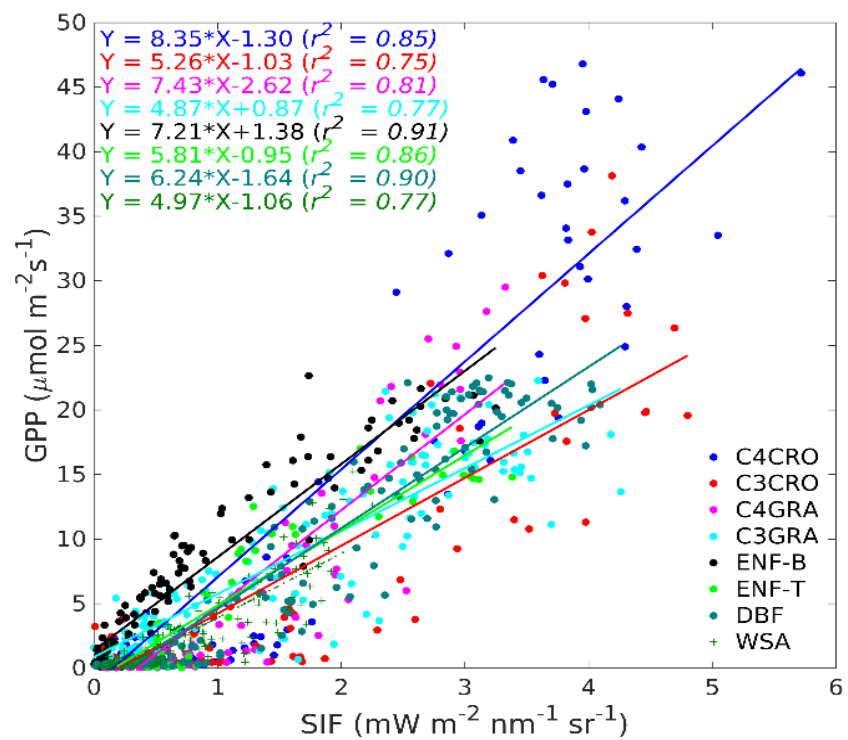

Fig. 8. Relationships between flux tower GPP and GOME-2 SIF for 16-day time bins across biomes.

First, we extracted the data at the morning and midday overpass time from the hourly simulations of the whole daytime. The modeled instantaneous (hourly) GPP-SIF curve at the morning time of satellite overpass (Fig. 9) indicates a non-linear correlation between GPP and SIF at both leaf and canopy level. This is generally similar to the relationship for the whole daytime (Figure 4). However, the non-linearity is weaker in the morning overpass time than that over the whole daytime (Fig. 9 and Fig. 4a, c \&e, g) because the morning conditions are generally more close to the linear range of GPP and SIF responding to light as shown in Fig. 2. The midday simulations show a stronger non-linearity between GPP and SIF due to the saturation of photosynthesis (Figure S10). 
To be consistent with satellite studies that usually compared point observations of SIF with the daily integrated GPP, we also examine the relationship between instantaneous (point) simulations of SIF and daily integrated GPP in the units of $\mathrm{g} \mathrm{C} \mathrm{m}^{-2} \mathrm{~d}^{-1}$ (see Fig. 10 for two selected biomes). Figure 10 shows how hourly SIF at the morning satellite overpass time relates to daily integrated GPP (green cross) from the simulations. Meanwhile, by comparing the average of morning SIF with daily integrated GPP at 16-day scale, we are able to demonstrate the effects of temporal aggregation on the GPP-SIF relationship (Fig.10). Similar to the temporal aggregation in Figure 4, the relationship becomes linear at the seasonal scale for the hourly simulations of SIF and GPP integrated over time. In addition, no significant differences are observed between the morning and midday overpass time for the relationship of SIF and integrated GPP at the seasonal scale because average conditions tend to fall within the linear range, as stated in Section 3.1.
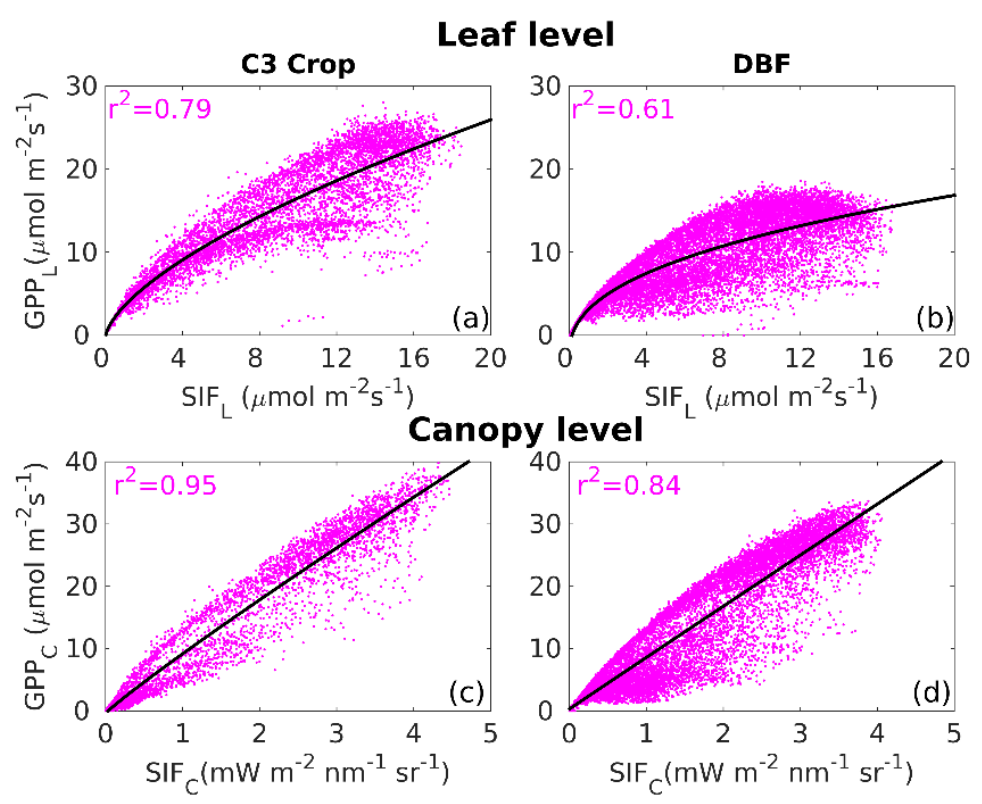

Fig. 9. Relationships between hourly GPP and hourly SIF for the morning overpass time (9-11 am) for two selected biomes at the leaf and canopy levels from SCOPE simulations.

These results support previous investigations and the consistency of the linear GPP-SIF relationship from the retrievals of GOME-2 (morning) and GOSAT (midday). Recent studies have shown a linear relationship between modeled GPP and SIF derived from space-borne 
measurements at both coarse spatial and seasonal scales (Frankenberg et al., 2011; Guanter et al., 2012; 2014). With simulations across diverse vegetation types and sites, our findings supported the hypothesis of a linear relationship between GPP and SIF derived from spaceborne measurements at the site scale, which is of great value for remote sensing of SIF because satellite observations are generally available for a snapshot once in a day, either in the morning or at midday. In addition, satellite data are generally aggregated over larger time scales (e.g., weekly to monthly) due to the many missing days of data caused by cloud cover.
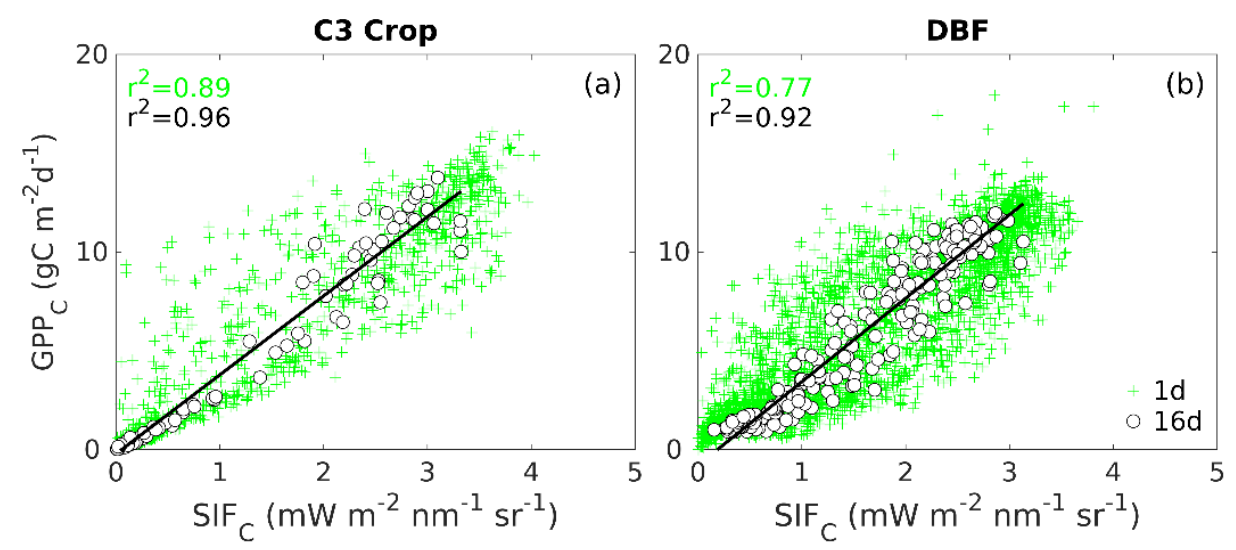

Fig. 10. Modeled canopy level relationships between integrated GPP $\left(\mathrm{gC} \mathrm{m}^{-2} \mathrm{~d}^{-1}\right)$ and hourly SIF for the morning overpass time at daily (green cross) and 16-day time scale (white circle) for two selected biomes. Note the different units for GPP between Figs. 4 and 10.

Furthermore, analysis of the influence of different overpass times (morning vs. midday) indicates that the GPP-SIF relationship is stronger in the morning than at midday from the instantaneous to the synoptic scale at the leaf level (Fig.11). For example, the 16-day mean SIF for the C3 Crop and DBF biomes has a higher correlation with GPP in the morning (rmse $=1.70, \mathrm{r}^{2}=0.89$ and $\mathrm{rmse}=1.34, \mathrm{r}^{2}=0.88$, respectively) than at midday ( $\mathrm{rmse}=2.21, \mathrm{r}^{2}=$ 0.69 , and rmse $=1.67, \mathrm{r}^{2}=0.70$, respectively) (Fig. 11), possibly due to the midday photosynthetic down-regulation of plants which is related to photo-inhibition under high light stress. 


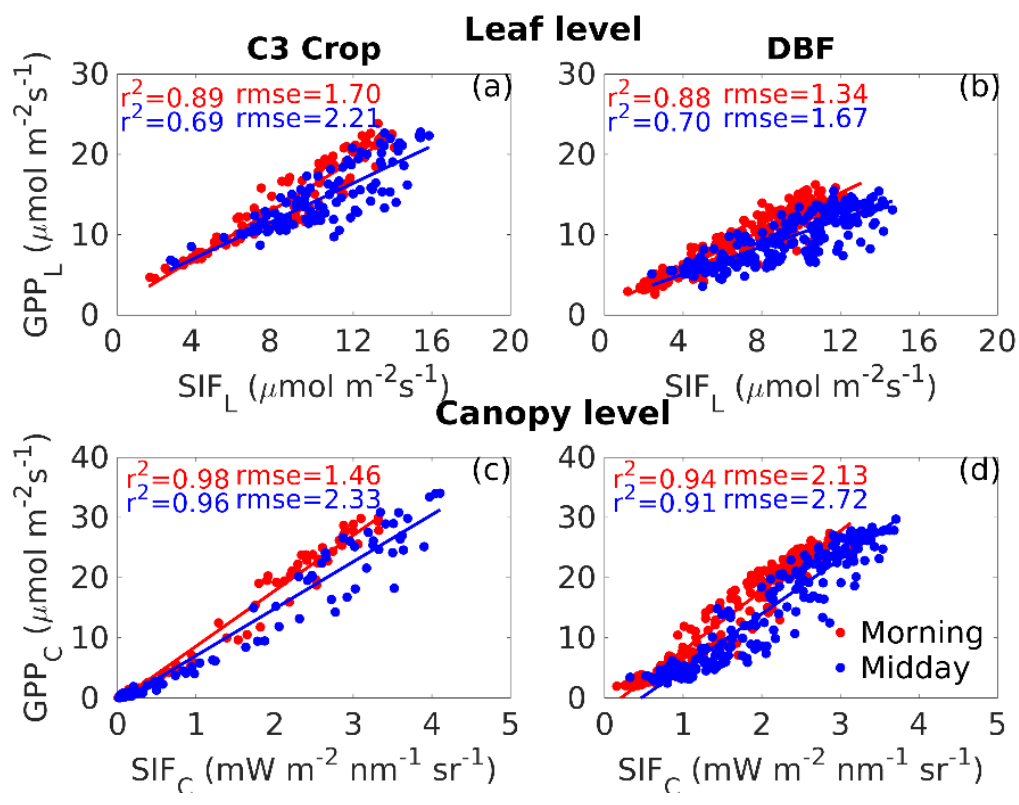

Fig. 11. Modeled leaf and canopy level relationships between GPP and SIF at 16-day time scales for the morning $(\mathbf{a}, \mathbf{b})$ and midday $(\mathbf{c}, \mathbf{d})$ overpass times for two selected biomes.

In contrast with the leaf level, the obvious differences in the GPP-SIF relationship were not observed between morning and midday at the canopy level. As shown in Fig. 11 (c, d), the GPP-SIF relationships have similar linearity between morning and midday with similar $\mathrm{r}^{2}$ values of the regression lines, except for slightly higher slope in the morning. The field canopy measurements also showed similar linearity of GPP-SIF relationship between morning and midday at canopy level at Harvard forest, but with a higher slope in the morning (Yang et al., 2015). One factor contributing to this similarity of the GPP-SIF relationship between morning and midday might be that both morning and midday GPP have a very similar relationship with daily GPP (Sims, et al., 2005). This is also true for SIF. The results also indicate that midday down-regulation of photosynthesis was not a significant factor in the GPP-SIF relationship at the canopy level compared with the leaf level, especially at the seasonal scale.

\subsection{Effects of spectral domain on the relationship between GPP and SIF}

The chlorophyll fluorescence spectrum has two emission peaks: in the red, at approximately $685 \mathrm{~nm}$, and in the far-red, at approximately $740 \mathrm{~nm}$. We examined the 
impacts of sampling these two peaks in relation to GPP to better interpret the space-borne SIF data such as GOME-2 red and far-red SIF data (Wolanin et al., 2015) and the Fluorescence Explorer (FLEX) mission.

Because no SIF emission spectrum is included in the output from SCOPE at the leaf level, only the canopy-level simulations are shown. This is also relevant to satellite retrieval of SIF. The comparison of GPP-SIF relationships for the red and far-red SIF for the C3 crop at 16day time step is shown in Figure 12a. This relationship is slightly better for the far-red SIF but not significant, with quite similar $r^{2}$ and rmse characterizing the goodness-of-fit for the two peaks (Fig. 12a). The similarities are consistent across diverse vegetation types at instantaneous and daily scales (Fig. 12(b, c)). The slope of the GPP-SIF relationship is larger for red SIF because red SIF values are generally less than far-red SIF values from SCOPE simulations at the canopy level. Several previous studies have suggested the use of two peaks of the SIF emission spectrum for improving the application of SIF as a constraint of GPP (Rossini et al., 2015; Verrelst et al., 2015). However, retrieving of red SIF data remains challenging due to weaker Fraunhofer lines and the non-linear shape of the surface reflectance in the red-edge range. In addition, considering the reabsorption of red SIF by chlorophyll itself within a leaf or inside a plant canopy (Gitelson et al., 1998), far-red SIF may currently be better for assessing terrestrial photosynthesis through remote sensing. Far-red SIF also contains clear information regarding the photosynthetic activity of the vegetation and is not reabsorbed during radiative transfer in the canopy (Daumard et al., 2012).

Both the photosystem I (PSI) and photosystem II (PS II) of chloroplasts are involved in fluorescence emission, but with different spectral and efficiency characteristics (Genty et al., 1990; Franck et al., 2002). The contribution of PSII to total fluorescence emission is greater in the red than in the far-red, while PSI emission spectrum shows a peak in the far-red (Franck et al., 2002). However, the dynamics of chlorophyll fluorescence are usually associated with PSII photochemistry because the contribution of fluorescence from PSI is generally low to 
total signal and remains constant under illumination (Genty et al., 1990; Palombi et al., 2011). Hence, PSI fluorescence is often assumed not to change with photochemistry (Pedrós et al., 2010; Porcar-Castell et al., 2014). This is also the assumption in the SCOPE model (van der Tol et al., 2014). However, these findings were generally from leaf-level studies at short time scales. Whether the hypothesis of a constant contribution from PSI remains at the seasonal scale is unknown and requires further validation (Porcar-Castell et al., 2014). Further study is needed to address these issues, especially with long-term ground measurements for retrievals of red SIF.
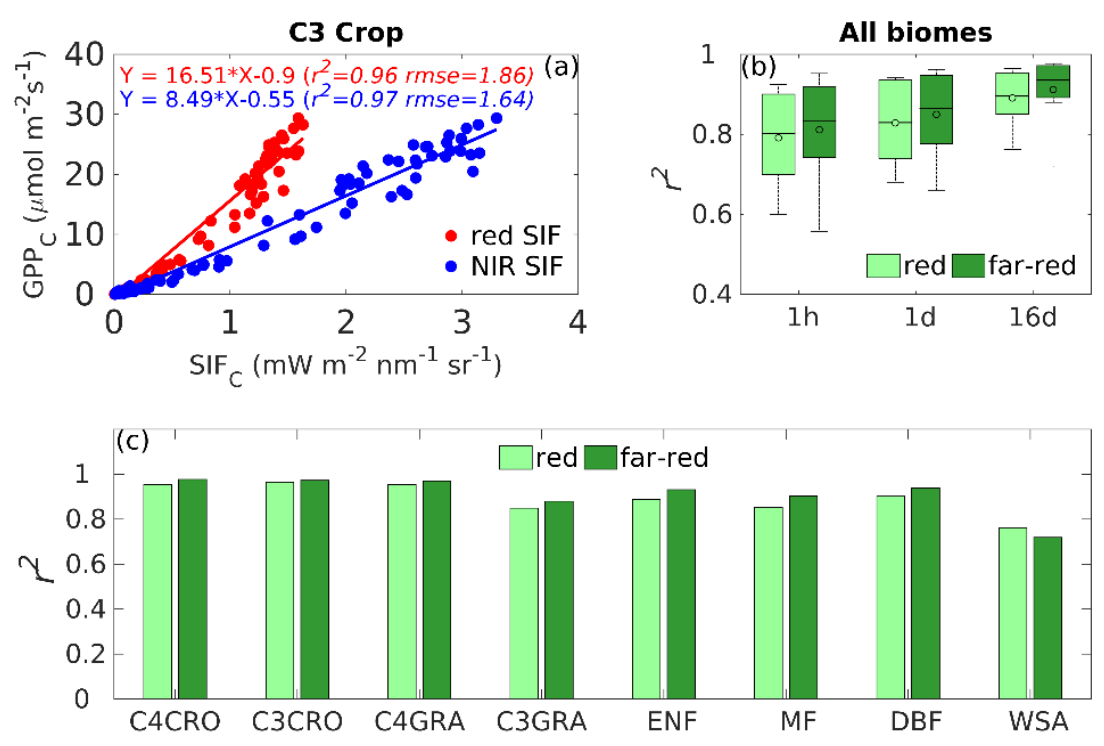

Fig. 12. Canopy level relationships between GPP and SIF for red SIF and far-red SIF from SCOPE simulations. (a) An example for the C3 Crop at 16-day time steps; (b) canopy level linear correlation $\left(r^{2}\right)$ between GPP and SIF for the average of all biomes at hourly (1h), daily (1d) and 16-day (16d) time scales; (c) canopy level linear correlation $\left(\mathrm{r}^{2}\right)$ between GPP and SIF across biomes at the instantaneous (hourly) time scale.

\subsection{Caveats and implications}

Some limitations of our model-based analysis are worth noting due to the uncertainty of the model assumptions and parameterizations. In SCOPE, for example, fluorescence yield was empirically calibrated with a rate constant for non-photochemical quenching, $K_{n}$, from active PAM fluorescence measurements of some species. This calibration model may vary with species and environmental conditions (van der Tol et al., 2014). Meanwhile, in the model 
parameterization, we assumed constant values for a few parameters such as $V_{c m a x}$ and leaf angle distribution for each vegetation type. These parameters are known to vary substantially in space and time (e.g., Wilson et al., 2001) and are crucial for mass and energy balance modeling (Bonan et al., 2011; Zhang et al., 2014). Ignoring the variations in these parameters would yield uncertainties in the model simulations. To quantify and reduce uncertainties caused by these model parameterizations, spatially and temporally explicit data sets are required. However, accurate measurements or estimations of these variables remain a substantial challenge.

Our model simulations may also be limited because of the potential impacts of complex radiative transfer within the canopy. The SCOPE model assumes $1 \mathrm{D}$ (vertical) radiative transfer based on the four-stream SAIL model (Verhoef, 1984; van der Tol et al., 2009b). This assumption may be suitable for relatively homogenous canopies (e.g., crops) but may introduce a large bias for heterogeneous canopies with clumping at several scales (e.g., forests) due to the intrinsic limitations of SAIL (Jacquemoud et al., 2009). Further improvements are needed to account for a more complex canopy architecture and leaf clumping. Furthermore, more measurements of GPP and SIF together, along with ground-validated modelling, are needed for the assessment of the relationship between GPP and SIF for different ecosystems, especially for the red peak of SIF.

\section{Conclusions}

In this study, we used SCOPE model simulations to assess the relationship between GPP and SIF at the leaf and canopy levels across different time scales and for diverse vegetation types and sites. We also compared the simulations with ground measurements as a preliminary evaluation. Our results show a curvilinear relationship between instantaneous GPP and SIF at the leaf level due to the photosynthesis light saturation under high illumination. This relationship tends to become linear when scaled to the canopy level likely 
because of the confounding effects of canopy structure and APAR, which cause the overall conditions of a canopy to fall within the linear range. Furthermore, temporal aggregation also linearizes the relationship between GPP and SIF, especially at seasonal scale, because of the dependency of both on APAR. These results were confirmed by field measurements. These relationships were also consistent across diverse vegetation types.

We also found that the relationships between simulated GPP and SIF are similar regardless of whether we used the morning or midday satellite overpass times, especially after temporal aggregation, which is consistent with the field measurements. Such similarity is of great interest for the remote sensing of vegetation with SIF because satellite measurements are generally collected by once daily overpass. In addition, we also demonstrate that simulated red SIF has a relationship with GPP similar to that of far-red SIF at the canopy level. Considering the greater challenge involved in the retrieval and reabsorption of red SIF, far-red SIF may currently be a better method to assess terrestrial photosynthesis. However, more future work, especially field study, is required to validate this finding.

\section{ACKNOWLEDGMENTS}

This research was financially supported by General Program of National Science Foundation of China (41671421), the National Key R\&D Program of China (2016YFA0600200) and the Thousand Young Talents Program in China (YZ) and the Emmy Noether Programme (GlobFluo project) of the German Research Foundation (YZ and LG). MODIS MOD13 EVI/NDVI data were obtained from the MODIS LP DAAC archive and MERIS-MTCI from the Infoterra Ltd server. This work used eddy covariance data acquired by the AmeriFlux and the European Fluxes Database. We further thank the PIs of the flux tower sites: J. H., Prueger (USBr1, National Laboratory for Agriculture and the Environment), A. Suyker (USNe3, Univ. Nebraska), D.Y., Hollinger, (USHo1, USDA Forest Service Northeastern Forest Exp. Station), K., Novick (USMMS, Indiana University), J. W., Munger (USHa1, Harvard University), R., Scott (USSRM and USWkg, USDA-ARS Southwest Watershed Research Center), D. D., Baldocchi (USTon, University of California, Berkeley), N., Brunsell (USKon, Kansas University), K. Klumpp (FRLq1, INRA Clermont), Z., Nagy (HU-Bug, Szent Instván University), Andrej Varlagin (RUFyo, A.N. Severtsov Institute of Ecology and Evolution, Russian Academy of Sciences, Moscow, Russia), and T., Laurila (FISod, Finnish Meteorological 


\section{REFERENCES}

Baldocchi, D. D., and J. S. Amthor (2001), Canopy photosynthesis: History, measurements, and models, Terrestrial global productivity, pp. 9 - 31 .

Beer, C., et al. (2010), Terrestrial gross carbon dioxide uptake: Global distribution and covariation with climate, Science, 329(5993), 834-838.

Bonan, G. B., P. J. Lawrence, K. W. Oleson, S. Levis, M. Jung, M. Reichstein, D. M. Lawrence, and S. C. Swenson (2011), Improving canopy processes in the community land model version 4 (clm4) using global flux fields empirically inferred from FluxNet data, Journal of Geophysical Research: Biogeosciences (2005-2012), 116(G2).

Brunsell, N., J. Ham, and C. Owensby (2008), Assessing the multi-resolution information content of remotely sensed variables and elevation for evapotranspiration in a tall-grass prairie environment, Remote Sensing of Environment, 112(6), 2977-2987.

Cogliati, S., M. Rossini, T. Julitta, M. Meroni, et al. (2015). Continuous and long-term measurements of reflectance and sun-induced chlorophyll fluorescence by using novel automated field spectroscopy systems, Remote Sensing of Environment, 164, 270-281.

Damm A, Elbers J, Erler A, et al. (2010) Remote sensing of sun-induced fluorescence to improve modeling of diurnal courses of gross primary production (GPP). Global Change Biology, 16, 171-186.

Damm, A., L. Guanter, E. Paul-Limoges, C. van der Tol, A. Hueni, N. Buchmann, W. Eugster, C. Ammann, and M. Schaepman (2015), Far-red sun-induced chlorophyll fluorescence shows ecosystem-specific relationships to gross primary production: An assessment based on observational and modeling approaches, Remote Sensing of Environment, 166, 91-105.

Dash, J., and P. Curran (2004), The MERIS terrestrial chlorophyll index, International Journal of Remote Sensing, 25, 5003-5013.

Daumard, F., Y. Goulas, S. Champagne, A. Fournier, A. Ounis, A. Olioso, and I. Moya (2012), Continuous monitoring of canopy level sun-induced chlorophyll fluorescence during the growth of a sorghum field, Geoscience and Remote Sensing, IEEE Transactions on, 50(11), 4292-4300.

Flexas, J., J. M. Escalona, S. Evain, J. Gulías, I. Moya, C. B. Osmond, and H. Medrano (2002), Steadystate chlorophyll fluorescence ( $\mathrm{fs}$ ) measurements as a tool to follow variations of net co2 assimilation and stomatal conductance during water-stress in c3 plants, Physiologia Plantarum, 114(2), 231-240.

Franck, F., P. Juneau, and R. Popovic (2002), Resolution of the photosystem i and photosystem ii contributions to chlorophyll fluorescence of intact leaves at room temperature, Biochimica et Biophysica Acta (BBA)-Bioenergetics, 1556(2), 239-246.

Frankenberg, C., J.B. Fisher, J. Worden, et al. et al. (2011), New global observations of the terrestrial carbon cycle from GOSAT: Patterns of plant fluorescence with gross primary productivity, Geophysical Research Letters, 38, L17, 706, doi:10.1029/2011GL048738.

Friedl, M. A., D. Sulla-Menashe, B. Tan, A. Schneider, N. Ramankutty, A. Sibley, and X. Huang (2010), Modis collection 5 global land cover: Algorithm refinements and characterization of new datasets, Remote Sensing of Environment, 114(1), 168-182. 
Gamon, J. A., J. Peñuelas, and C. B. Field (1992), A narrow-waveband spectral index that tracks diurnal changes in photosynthetic efficiency, Remote Sensing of Environment, 41, 35-44.

Genty, B., J. Harbinson, N. Baker, et al. (1990), Relative quantum efficiencies of the two photosystems of leaves in photorespiratory and non-respiratory conditions., Plant Physiology and Biochemistry (Paris), 28(1), 1-10.

Gitelson, A. A., C. Buschmann, and H. K. Lichtenthaler (1998), Leaf chlorophyll fluorescence corrected for re-absorption by means of absorption and reflectance measurements, Journal of plant physiology, 152(2), 283-296.

Grace, J., C. Nichol, M. Disney, P. Lewis, T. Quaife, and P. Bowyer (2007), Can we measure terrestrial photosynthesis from space directly, using spectral reflectance and fluorescence?, Global Change Biology, 13(7), 1484-1497.

Guanter, L., C. Frankenberg, A. Dudhia, P. E. Lewis, J. Gómez-Dans, A. Kuze, H. Suto, and R. G. Grainger (2012), Retrieval and global assessment of terrestrial chlorophyll fluorescence from GOSAT space measurements, Remote Sensing of Environment, 121, 236-251.

Guanter, L., et al. (2014), Global and time-resolved monitoring of crop photosynthesis with chlorophyll fluorescence, Proceedings of the National Academy of Sciences, 111(14), E1327-E1333.

Hollinger, D., et al. (2004), Spatial and temporal variability in forest-atmosphere co2 exchange, Global Change Biology, 10(10), 1689-1706.

Huete, A., K. Didan, T. Miura, E. Rodriguez, X. Gao, and L. Ferreira (2002), Overview of the radiometric and biophysical performance of the modis vegetation indices, Remote Sensing of Environment, 83(12), 195 - 213.

Hussain, M., T. Grünwald, J.D. Tenhunen, Y.L. Li, H. Mirzae, C. Bernhofer, D. Otieno, et al. (2011), Summer drought influence on $\mathrm{co}_{2}$ and water fluxes of extensively managed grassland in Germany, Agriculture, Ecosystems \& Environment, 141(1), 67-76.

Jacquemoud, S., W. Verhoef, F. Baret, C. Bacour, P. J. Zarco-Tejada, G. P. Asner, C. FranÃßois, and S. L. Ustin (2009), Prospect+sail models: A review of use for vegetation characterization, Remote Sensing of Environment, 113, Supplement 1(0), S56 - S66, Imaging Spectroscopy Special Issue.

Joiner, J., Y. Yoshida, A. P. Vasilkov, Y. Yoshida, L. A. Corp, and E. M. Middleton (2011), First observations of global and seasonal terrestrial chlorophyll fluorescence from space, Biogeosciences, $8(3), 637-651$.

Joiner, J., Y. Yoshida, A. P. Vasilkov, E. M. Middleton, P. K. E. Campbell, Y. Yoshida, A. Kuze, and L. A. Corp (2012), Filling-in of near-infrared solar lines by terrestrial fluorescence and other geophysical effects: simulations and space-based observations from sciamachy and gosat, Atmospheric Measurement Techniques, 5 (4), 809-829.

Joiner, J., L. Guanter, R. Lindstrot, M. Voigt, A. P. Vasilkov, E. M. Middleton, K. F. Huemmrich, Y. Yoshida, and C. Frankenberg (2013), Global monitoring of terrestrial chlorophyll fluorescence from moderatespectral-resolution near-infrared satellite measurements: methodology, simulations, and application to GOME-2, Atmospheric Measurement Techniques, 6(10), 2803-2823. 
Joiner, J., Y. Yoshida, A.P. Vasilkov, K. Schaefer, M. Jung, L. Guanter, Y. Zhang, S. Garrity, et al. (2014), The seasonal cycle of satellite chlorophyll fluorescence observations and its relationship to vegetation phenology and ecosystem atmosphere carbon exchange, Remote Sensing of Environment, 152, 375391.

Kattge, J., W. Knorr, T. Raddatz, and C. Wirth (2009), Quantifying photosynthetic capacity and its relationship to leaf nitrogen content for global-scale terrestrial biosphere models, Global Change Biology, 15(4), 976-991.

Klumpp, K., T. Tallec, N. Guix, and J.-F. Soussana (2011), Long-term impacts of agricultural practices and climatic variability on carbon storage in a permanent pasture, Global Change Biology, 17(12), 35343545 .

Knyazikhin, Y., M.A. Schull, P. Stenberg, M. Mõttus, M. Rautiainen,Y. Yang, et al. (2012), Hyperspectral remote sensing of foliar nitrogen content, Proceedings of the National Academy of Sciences, 110(3), E185-E192.

Koffi, E. N., P. J. Rayner, A. J. Norton, C. Frankenberg, and M. Scholze (2015), Investigating the usefulness of satellite-derived fluorescence data in inferring gross primary productivity within the carbon cycle data assimilation system, Biogeosciences, 12 (13), 4067-4084, doi:10.5194/ bg-124067-2015.

Köhler, P., L. Guanter, and C. Frankenberg (2015a), Simplified physically based retrieval of sun-induced chlorophyll fluorescence from gosat data, Geoscience and Remote Sensing Letters, IEEE, 12 (7), 1446-1450, doi: 10.1109/LGRS.2015.2407051.

Köhler, P., L. Guanter, and J. Joiner (2015b), A linear method for the retrieval of sun-induced chlorophyll fluorescence from gome-2 and sciamachy data, Atmospheric Measurement Techniques, 8(6), 25892608, doi: rm10.5194/amt-8-2589-2015.

Lee, J.-E., C.Frankenberg, C. van der Tol, J. A. Berry, L. Guanter, C. K. Boyce, et al. (2013), Forest productivity and water stress in Amazonia: observations from GOSAT chlorophyll fluorescence, Proceedings of the Royal Society B: Biological Sciences, 280(1761), doi: rm10.1098/rspb.2013.0171.

Meroni, M., A. Barducci, S. Cogliati, F. Castagnoli, M. Rossini, et al. (2011). The hyperspectral irradiometer, a new instrument for long-term and unattended field spectroscopy measurements. Review of Scientific Instruments, 82, 1-9.

Palombi, L., G. Cecchi, D. Lognoli, V. Raimondi, G. Toci, and G. Agati (2011), A retrieval algorithm to evaluate the photosystem I and photosystem II spectral contributions to leaf chlorophyll fluorescence at physiological temperatures, Photosynthesis research, 108(2-3), 225-239.

Papale D, Reichstein M, Aubinet M, et al. (2006), Towards a standardized processing of net ecosystem exchange measured with eddy covariance technique: algorithms and uncertainty estimation, Biogeosciences, 3(4), 571-583.

Pedrós, R., Y. Goulas, S. Jacquemoud, J. Louis, and I. Moya (2010), Fluormodleaf: A new leaf fluorescence emission model based on the prospect model, Remote Sensing of Environment, 114(1), 155-167.

Porcar-Castell, A., E. Juurola, I. Ensminger, F. Berninger, P. Hari, and E. Nikinmaa (2008), Seasonal acclimation of photosystem II in pinus sylvestris. II: using the rate constants of sustained thermal 
energy dissipation and photochemistry to study the effect of the light environment, Tree physiology, 28(10), 1483-1491.

Porcar-Castell, A., E. Tyystjärvi, J. Atherton, C. van der Tol, J. Flexas, E. E. Pfündel, J. Moreno, C. Frankenberg, and J. A. Berry (2014), Linking chlorophyll fluorescence to photosynthesis for remote sensing applications: mechanisms and challenges, Journal of Experimental Botany, 65(15), 4065-4095.

Rascher, U., et al. (2015), Sun-induced fluorescence-a new probe of photosynthesis: First maps from the imaging spectrometer Hyplant, Global change biology, 21(12), 4673-4684.

Reichstein, M., E. Falge, D. Baldocchi, D. Papale, M. Aubinet, P. Berbigier, et al. (2005), On the separation of net ecosystem exchange into assimilation and ecosystem respiration: review and improved algorithm, Global Change Biology, 11(9), 1424-1439.

Rossini, M., M. Meroni, M. Migliavacca, G. Manca, S. Cogliati, L. Busetto, et al. (2010). High resolution field spectroscopy measurements for estimating gross ecosystem production in a rice field. Agricultural and Forest Meteorology, 150, 1283-1296.

Rossini, M., L. Nedbal, L. Guanter, A. Ač, L. Alonso, A. Burkart, et al.et al. (2015), Red and far red suninduced chlorophyll fluorescence as a measure of plant photosynthesis, Geophysical research letters, 42(6), 1632-1639.

Ruimy, A., P. Jarvis, D. Baldocchi, and B. Saugier (1995), Co2 fluxes over plant canopies and solar radiation: a review, Advances in Ecological Research (United Kingdom).

Sauer, T. J., J. W. Singer, J. H. Prueger, T. M. DeSutter, and J. L. Hatfield (2007), Radiation balance and evaporation partitioning in a narrow-row soybean canopy, Agricultural and Forest Meteorology, 145(3), 206-214.

Schaefer, K., et al. (2012), A model-data comparison of gross primary productivity: Results from the North American Carbon Program site synthesis, J. Geophys. Res.: Biogeosciences, 117(G3).

Schmid, H. P., C. S. B. Grimmond, F. Cropley, B. Offerle, and H.-B. Su (2000), Measurements of co 2 and energy fluxes over a mixed hardwood forest in the mid-western United States, Agricultural and Forest Meteorology, 103(4), 357-374.

Scott, R. L., W. L. Cable, and K. R. Hultine (2008), The ecohydrologic significance of hydraulic redistribution in a semiarid savanna, Water Resources Research, 44(2).

Sims, D. A., et al. (2005), Midday values of gross co 2 flux and light use efficiency during satellite overpasses can be used to directly estimate eight-day mean flux, Agricultural and Forest Meteorology, 131(1), 1-12.

Stoy, P. C., A. M. Trowbridge, and W. L. Bauerle (2014), Controls on seasonal patterns of maximum ecosystem carbon uptake and canopy-scale photosynthetic light response: contributions from both temperature and photoperiod, Photosynthesis research, 119(1-2), 49-64.

Sulkava, M., S. Luyssaert, S. Zaehle, and D. Papale (2011), Assessing and improving the representativeness of monitoring networks: The european flux tower network example, Journal of Geophysical Research: Biogeosciences (2005-2012), 116(G3). 
Suyker, A. E., S. B. Verma, G. G. Burba, and T. J. Arkebauer (2005), Gross primary production and ecosystem respiration of irrigated maize and irrigated soybean during a growing season, Agricultural and Forest Meteorology, 131(3), 180-190.

van der Tol, C., W. Verhoef, and A. Rosema (2009a), A model for chlorophyll fluorescence and photosynthesis at leaf scale, Agricultural and Forest Meteorology, 149(1), 96 - 105.

van der Tol, C., W. Verhoef, J. Timmermans, A. Verhoef, and Z. Su (2009b), An integrated model of soilcanopy spectral radiances, photosynthesis, fluorescence, temperature and energy balance, Biogeosciences, 6, 3109-3129.

van der Tol, C., J. Berry, P. Campbell, and U. Rascher (2014), Models of fluorescence and photosynthesis for interpreting measurements of solar-induced chlorophyll fluorescence, Journal of Geophysical Research: Biogeosciences, 119(12), 2312-2327.

van Wittenberghe, S., L. Alonso, J. Verrelst, J. Moreno, and R. Samson (2015), Bidirectional sun-induced chlorophyll fluorescence emission is influenced by leaf structure and light scattering properties a bottom-up approach, Remote Sensing of Environment, 158, 169-179.

Verhoef, W. (1984), Light scattering by leaf layers with application to canopy reflectance modeling: the sail model, Remote sensing of environment, 16(2), 125-141.

Verrelst, J., J. P. Rivera, C. van der Tol, F. Magnani, G. Mohammed, and J. Moreno (2015), Global sensitivity analysis of the scope model: What drives simulated canopy-leaving sun-induced fluorescence? Remote Sensing of Environment, 166, 8-21.

Wang, Y., and P. Jarvis (1990), Influence of crown structural properties on par absorption, photosynthesis, and transpiration in sitka spruce: application of a model (maestro), Tree physiology, 7(1-2-3-4), 297316.

Wilson, K., D. Baldocchi, and P. Hanson (2001), Leaf age affects the seasonal pattern of photosynthetic capacityand net ecosystem exchange of carbon in a deciduous forest, Plant, Cell \& Environment, 24(6), 571-583.

Wofsy, S., M. Goulden, J. Munger, S.-M. Fan, P. Bakwin, B. Daube, S. Bassow, and F. Bazzaz (1993), Net exchange of $\operatorname{co} 2$ in a mid-latitude forest, Science, 260(5112).

Wolanin, A., V. Rozanov, T. Dinter, S. No“el, M. Vountas, J. Burrows, and A. Bracher (2015), Global retrieval of marine and terrestrial chlorophyll fluorescence at its red peak using hyperspectral top of atmosphere radiance measurements: Feasibility study and first results, Remote Sensing of Environment, 166, 243-261.

Wullschleger, S. D. (1993), Biochemical limitations to carbon assimilation in c3 plantsa retrospective analysis of the a/ci curves from 109 species, Journal of Experimental Botany, 44(5), 907-920.

Xu, L., and D. D. Baldocchi (2003), Seasonal trends in photosynthetic parameters and stomatal conductance of blue oak (quercus douglasii) under prolonged summer drought and high temperature, Tree Physiology, 23(13), 865-877.

Yang, X., J. Tang, J. F. Mustard, J.-E. Lee, M. Rossini, J. Joiner, J. W. Munger, A. Kornfeld, and A. D. Richardson (2015), Solar-induced chlorophyll fluorescence that correlates with canopy photosynthesis 
on diurnal and seasonal scales in a temperate deciduous forest, Geophysical Research Letters, 42(8), 2977-2987.

Zhang, Y., L. Guanter, J. A. Berry, J. Joiner, C. van der Tol, A. Huete, A. Gitelson, M. Voigt, and P. Köhler (2014), Estimation of vegetation photosynthetic capacity from space-based measurements of chlorophyll fluorescence for terrestrial biosphere models, Global Change Biology, 20(12), 3727-3742. 


\section{List of Tables}

Table 1. Basic information for all the flux tower sites.

Table 2. Maximum carboxylation capacity (Vcmax) for each plant function type (PFT)

Table 3. Parameters of the SCOPE model for the sensitivity simulations and their range. 


\section{List of Figures}

Figure 1. (a) Relationships between flux tower GPP and field measured SIF (at $760 \mathrm{~nm}$ ) for all days from hourly to 16-day steps at the Harvard Forest site for 2013 for all daytime; (b) for the clear sky days. The black line is a linear regression for the 16-day time series. The cyan line is a power model fit for the hourly data. The different colors (cyan, green, and white) represent hourly (1h), daily (1d) and 16-day (16d) time scales, respectively. $r^{2}$ is the coefficient of linear regression.

Figure 2. Modeled GPP $\left(\mathrm{GPP}_{\mathrm{L}}\right)$ and $\mathrm{SIF}\left(\mathrm{SIF}_{\mathrm{L}}\right)$ at the leaf level (a) as a function of $V_{c \max }$ at different levels of light (Rin): 100, 300, 500, 700, 900 and $1100 \mathrm{~W} \mathrm{~m}^{-2}$; and (b) as a function of APAR at different levels of $V_{\text {cmax }}: 0,40,80,120,160$ and $200 \mu \mathrm{mol} \mathrm{m}^{-2} \mathrm{~s}^{-1}$. Leaf-level SIF is an approximation of fluorescence flux, which is the product of fluorescence yield $\left(\Phi_{F t}\right)$ and APAR.

Figure 3. Modeled leaf level relationships of fluorescence yield $\left(\Phi_{F t}\right)$ and photochemical yield $\left(\Phi_{p}\right)$ for two selected biomes (C3 crop and DBF). The different colors (cyan, green, and black) represent hourly (1h), daily (1d) and 16-day (16d) time scales, respectively. $\mathrm{r}^{2}$ is the coefficient of linear regression. The solid black line is the fit for 16-day time scale. See the plots for other biomes in Fig. S5 in the Supplement.

Figure 4. Changes in the relationships between GPP and SIF from leaf to canopy level and from instantaneous to synoptic scale for four selected biomes from SCOPE simulations. $\mathrm{SIF}_{\mathrm{L}}$, total leaf level fluorescence flux, was calculated as APAR $* \Phi_{F t}$. Leaf level GPP $\left(\mathrm{GPP}_{\mathrm{L}}\right)$ was directly obtained from the SCOPE output. GPP and SIF $\left(\mathrm{GPP}_{\mathrm{C}}\right.$ and $\left.\mathrm{SIF}_{\mathrm{C}}\right)$ at the canopy level are from SCOPE output. The different colors (magenta, red, and white) represent hourly (1h), daily (1d) and 16-day (16d) time scales, respectively. $\mathrm{r}^{2}$ is the coefficient of linear regression. The solid black line is the fit for the 16-day time scale.

Figure 5. Leaf and canopy level relationships between GPP\&SIF and APAR for two selected biomes (hourly, daily, and 16-day time scales) from SCOPE simulations. The different colors (magenta, red, and white) represent hourly (1h), daily (1d) and 16-day (16d) time scales, respectively. The solid black line is the fit for the 16-day time scale. See the plots for other biomes in Fig. S6-9 in the Supplement.

Figure 6. Leaf (a) and canopy (c) level linear correlation $\left(\mathrm{r}^{2}\right)$ between GPP and SIF or APAR across biomes at instantaneous (hourly) time scales from SCOPE simulations. (b) and (d) are the averages of all biomes at hourly (1h), daily (1d) and 16-day (16d) time scales for the leaf and canopy levels, respectively. The inset plot in (d) is the correlation between GPP and SIF or APAR from the field measurements at Harvard Forest.

Figure 7. The sensitivity of the relationship between hourly GPP and SIF at $740 \mathrm{~nm}$ to LAI (a), $\mathrm{V}_{\mathrm{cmax}}(\mathrm{b}), \mathrm{C}_{\mathrm{ab}}$ (c), and LIDFa (d) at the canopy level for a C3 plant from simulations. The radiation $(\mathrm{Rin})$ is from 100 to $1200 \mathrm{~W} \mathrm{~m}^{-2}$.

Figure 8. Relationships between flux tower GPP and GOME-2 SIF for 16-day time bins across biomes.

Figure 9. Relationships between hourly GPP and hourly SIF for the morning overpass time (9-11 am) for two selected biomes at the leaf and canopy levels from SCOPE simulations. 
Figure 10. Modeled canopy level relationships between integrated GPP $\left(\mathrm{gC} \mathrm{m}^{-2} \mathrm{~d}^{-1}\right)$ and hourly SIF for the morning overpass time at daily (green cross) and 16-day time scale (white circle) for two selected biomes. Note the different units for GPP between Figs. 4 and 10.

Figure 11. Modeled leaf and canopy level relationships between GPP and SIF at 16-day time scales for the morning $(\mathbf{a}, \mathbf{b})$ and midday $(\mathbf{c}, \mathbf{d})$ overpass times for two selected biomes.

Figure 12. Canopy level relationships between GPP and SIF for red SIF and far-red SIF from SCOPE simulations. (a) An example for the C3 Crop at 16-day time steps; (b) canopy level linear correlation $\left(\mathrm{r}^{2}\right)$ between GPP and SIF for the average of all biomes at hourly (1h), daily (1d) and 16-day (16d) time scales; (c) canopy level linear correlation ( $\left.\mathrm{r}^{2}\right)$ between GPP and SIF across biomes at the instantaneous (hourly) time scale. 